\title{
Advances in Health Monitoring and Management
}

\author{
Nezih Mrad $^{* 1}$ and Rim Lejmi-Mrad ${ }^{2}$ \\ ${ }^{1}$ Air Vehicles Research Section (AVRS), Defence R\&D Canada (DRDC), \\ Department of National Defence (DND), National Defence Headquarters Ottawa, Ontario, \\ ${ }^{2}$ Apoptosis Research Center (ARC), Children's Hospital Eastern Ontario (CHEO), \\ Department of Cellular \& Molecular Medicine, \\ Faculty of Medicine University of Ottawa, Ontario, \\ Canada
}

\section{Introduction}

Scientists in engineering, physical and health sciences continue to explore biological systems functions and behaviors to develop bio-inspired human and engineering complex systems, subsystems and components. In the natural sciences, it is demonstrated that such acquisition of knowledge is leading to tangible outcomes in the form of organs grow th and implants [1]. Critical human organs have been cultured in the lab from the cell level to a fully functional body parts (e.g. ear, kidney, heart). The advantages of this development are numerous and include increased quality of life and performance, increased life expectancy (life cycle), reduced health care costs and infrastructure (maintenance costs). It has also been demonstrated that an effective man-machine interface [2] has led not only to providing the disabled with a second chance at a higher quality of life, but at times of having even superior life quality, longevity and performance (e.g. artificial limps). Such accomplishments in science and technology are rendered possible by the exploitation of innovation and creative conceptualization, integration of advanced sensor technology, control systems and hybrid material systems. In the last decades and since the decoding of human deoxyribonucleic acid (DNA), significant effort has been expanded on the development of selective biological systems that are expected to be maintenance and disease free or possess some desired biological or functional characteristics (e.g. specific body or esthetic features). For instance, before fertilization, human eggs are screened for potential diseases and genes related to particular diseases are extracted and replaced by healthy ones [3], this is also known as gene therapy. It is well established that the human body is the most complex system that science has encountered. The exploration of this system, which is in its infancy, only now is providing clues and knowledge on how this system functions and how external parameters affect its performance and health. This knowledge has so far contributed to the society advancement in several sectors including health care, education, space exploration, economic and earth resources conservation. Additionally, acquired knowledge has contributed to new age efficient infrastructure development that includes infrastructure for communication, transportation, water, energy, and finance. 
As a result of advances in natural and biological sciences, current engineering systems, subsystems, components and platforms have increased and continue to increase in complexity. With advances in multifunctional materials, micro- and nano-fabrication, advanced integrated electronics, flexible circuitry and electronics, innovative power generation and optimal power consumption, artificial intelligence and creative data extraction, fusion, and interpretation, these complex systems are increasingly gaining autonomy and functionality. Several systems are now able to detect and adapt to anomalies (e.g. self-healing materials [4]). Current systems are continuously being designed for efficient manufacturing and materials usage, reduced reliance on human intervention, increased reliance on advanced and intelligent decision making capabilities and functionalities at reduced manufacturing, acquisition, and maintenance costs.

This document introduces the subject of health monitoring and management and its associated terminology. It also introduces the role of nature and biological systems in the design and development of complex multifunctional engineering systems. Finally, it presents some advances in engineering systems and systems components, particularly as they relate to the aerospace sector. It is not the intent of this document to provide detailed accounts for technology development, implementation and integration, but its objective is to highlight technological advances as well as technological and implementation challenges of health monitoring and management systems within different sectors of the industry, particularly the aerospace sector.

\section{Terminology and definitions}

\subsection{Systems}

The general definition of a system is a collection of pieces whose collective function is greater than the function of the individual pieces. Depending on the domain of interest, this definition could evolve to a more complex one. It is the opinion of the authors that the definition of a biological system constitutes the foundation for any evolving system. Hence, we define in the following only biological and engineering systems.

\subsubsection{Biological system}

A biological system (or organ system) is a group of organs that work together to perform a certain task, referred to as a functional task. Common systems, such as those present in mammals and other animals, seen also in human anatomy, are the circulatory system, the respiratory system, the nervous system, etc. Typically, the phrase referring to a "living system" or system containing biological entities is contained by a boundary, across which energy, matter, or work may pass. A typical example of a biological system is the cell, encased by a cell membrane. The term "biological system" is also referred to a system consisting essentially of biological processes [5-6]. In human anatomy, a human body system is a group of organs that work together to accomplish a bodily function. In the human body, cells combine to form tissues (e.g. skin tissues, muscle tissues, bone tissues), tissues combine and form organs, organs combine to form organ systems, and organ systems combine to form the human body. Examples of such human body systems, their functions and their corresponding organs include: digestion system (mouth, esophagus, stomach, large and small intestines), circulatory system (heart, veins, and arteries), muscular system (muscles), skeletal system (bones), nervous system (brain and nerve pathways), respiratory system (lungs), etc. 


\subsubsection{Engineering system}

An engineering system is a system that is technologically enabled, has significant sociotechnical interactions and has substantial complexity. Moses [7] presents some types and foundational issues with engineering systems. Engineering systems are interdisciplinary in nature and are devoted to addressing large-scale, complex engineering challenges within their socio-political context. These can further be defined as systems with diverse, complex, physical designs that may include components from several engineering disciplines, as well as economics, public policy, and other sciences. Some of the easiest systems to understand are mechanical systems. Simple systems are often constructed for a single purpose and generally have few parts or subsystems. For instance the cooling system in a car may consist of a radiator, a fan, a water pump, a thermostat, a cooling jacket, and several hoses and clamps. Together they function to keep the engine from overheating, but separately they are useless. Similar to biological systems, all system components must be present and they must be arranged in the proper way. Removing, misplacing or damaging one component puts the whole system out of commission.

\subsubsection{Biological-engineering system}

Biological-engineering systems also referred to as bioengineering systems, consist of interrelated and interdependent biological and engineering systems or objects. From the medical perspective, bioengineering integrates physical, chemical, or mathematical sciences and engineering principles for the study of biology, medicine, behavior, or health. It advances fundamental concepts, creates knowledge from the molecular to the organ systems levels, and develops innovative biologics, materials, processes, implants, and devices for the prevention, diagnosis, and treatment of disease, for patient rehabilitation, and for improving health. It is clear that bioengineering is concerned with applying an engineering approach (systematic, quantitative, and integrative) and an engineering focus (the solutions of problems) to biological problems, it is also concerned with applying biological knowledge and processes to engineering problems. From an engineering perspective, bioengineering systems are those that are built specifically to work in conjunction with the human body, often to amplify its capability and improve its performance. One of the most basic examples is the operation of a baseball bat or similar tools. The mechanical subsystem does nothing until it is combined with the human component of the system. While the biological component can do a whole lot without the tool, it would be hard pressed for the tool to perform its intended function. Cardiac pacemakers provide another, more complex, bioengineering example of the interrelated and interdependent biological and engineering systems.

Figure 1, represents a simplified perspective of a selected biological system [8-9]. Figure 2 [10] illustrates the human levels of organization from cellular to tissue, organ and organ system (human body). Within each cell is a biological and metabolic system that creates and uses energy that is necessary for the cell's life and function. There are many types of cells in the body, such as bone cells, muscle cells (myocytes), liver cells (hepatocytes), heart cells (cardiocytes), nerve cells, skin cells, and kidney cells. The latter are a large collection permitting the development of tissues hence the development of muscle tissues, connective, epithelial, and nervous tissues. Figure 3 [11-12] represent engineering and bioengineering systems, respectively. 

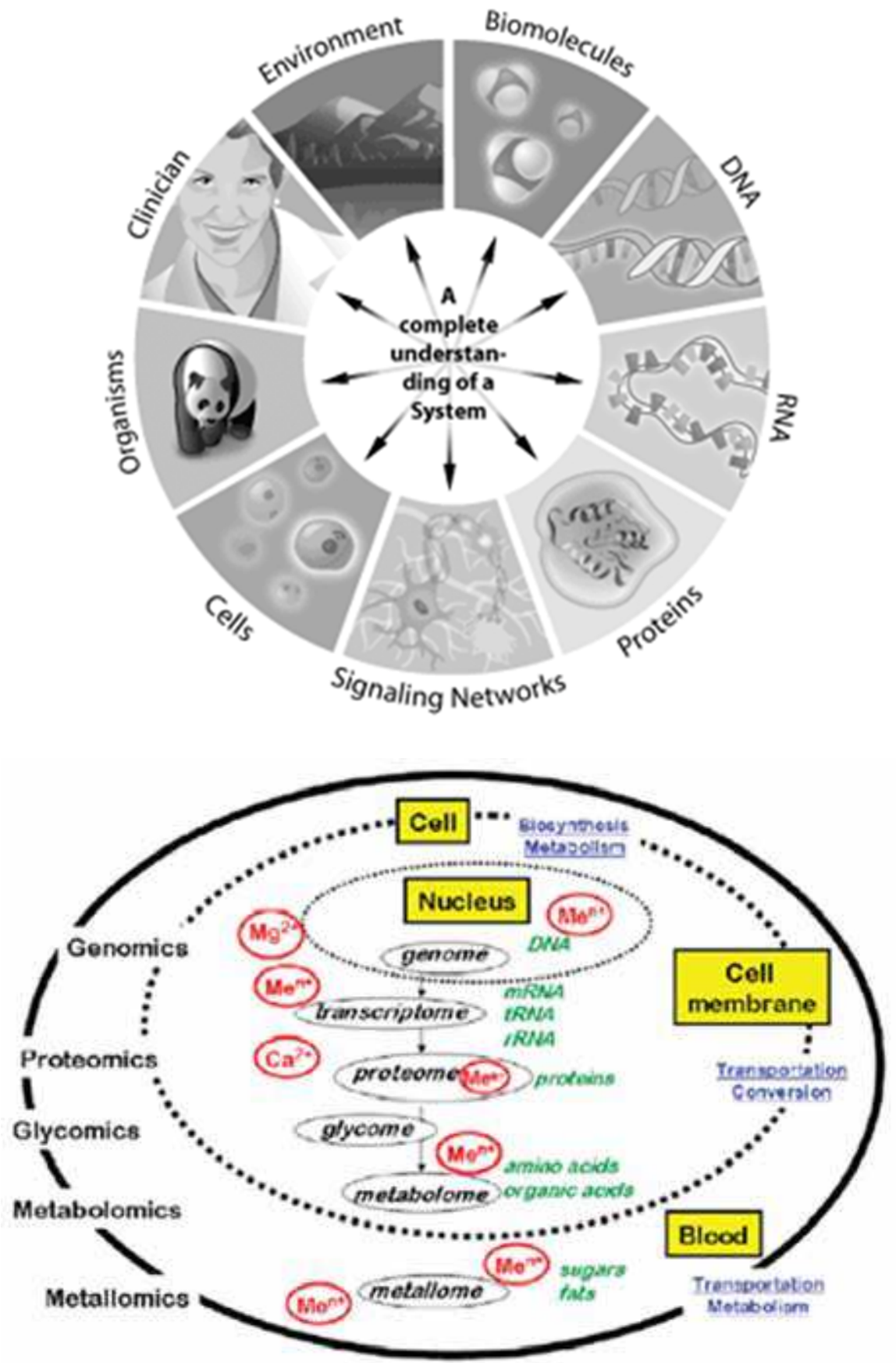

Fig. 1. Perspective and simplified model of a biological system. 


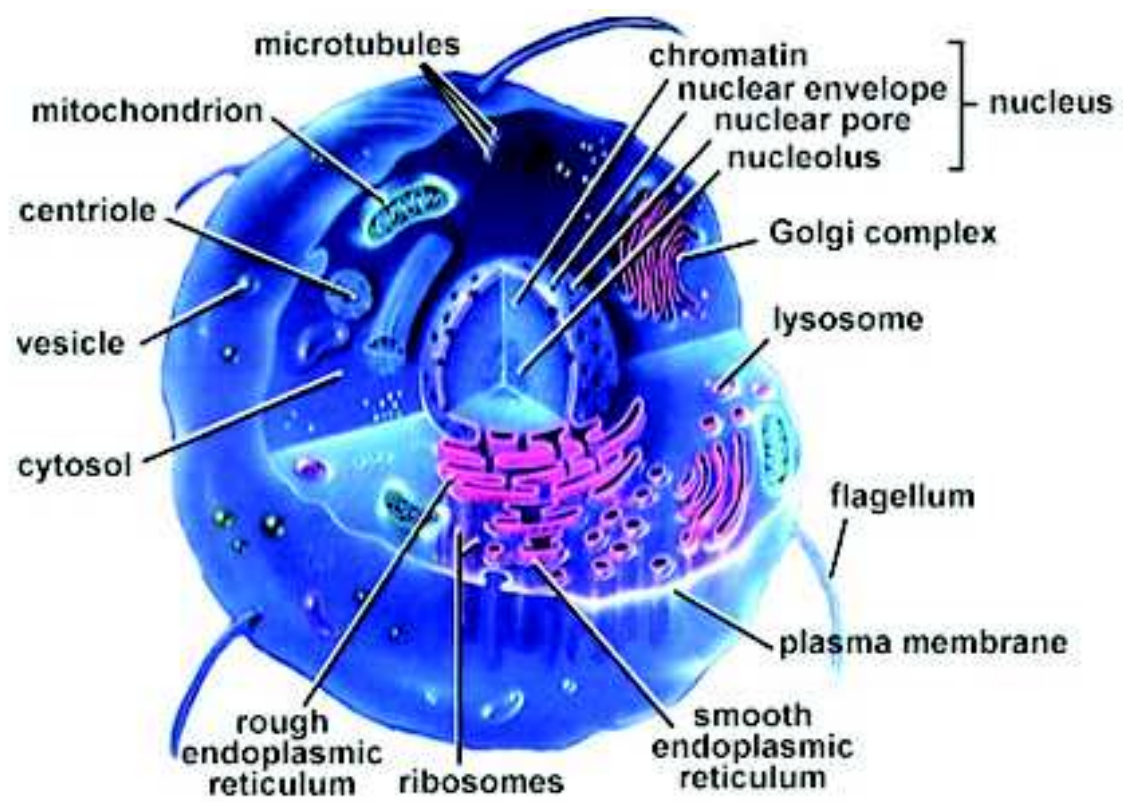

(a)

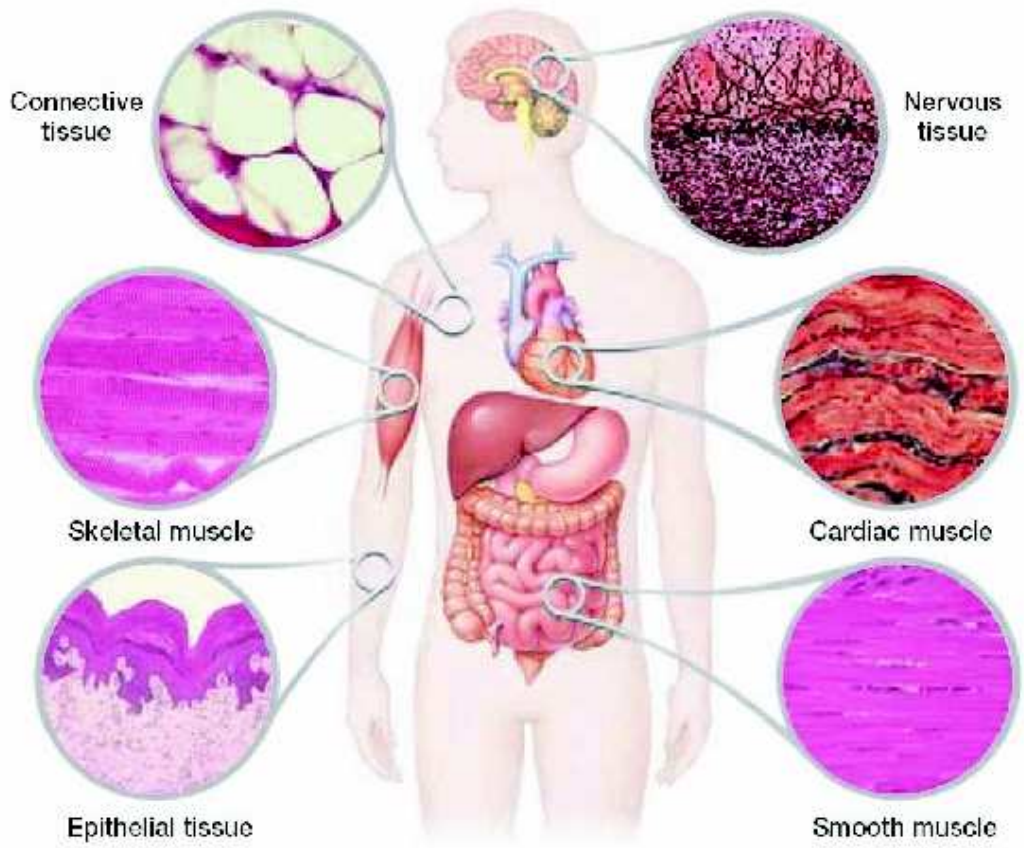

(b)

Fig. 2. Example of human cells, tissues, organs, and organ systems. 


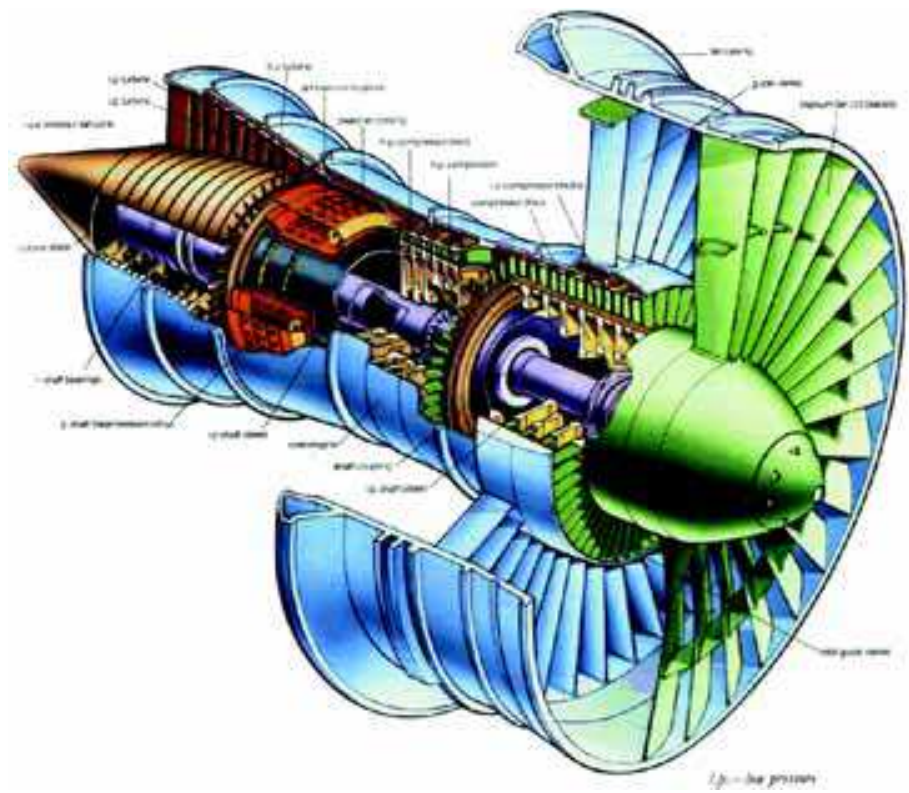

(a)

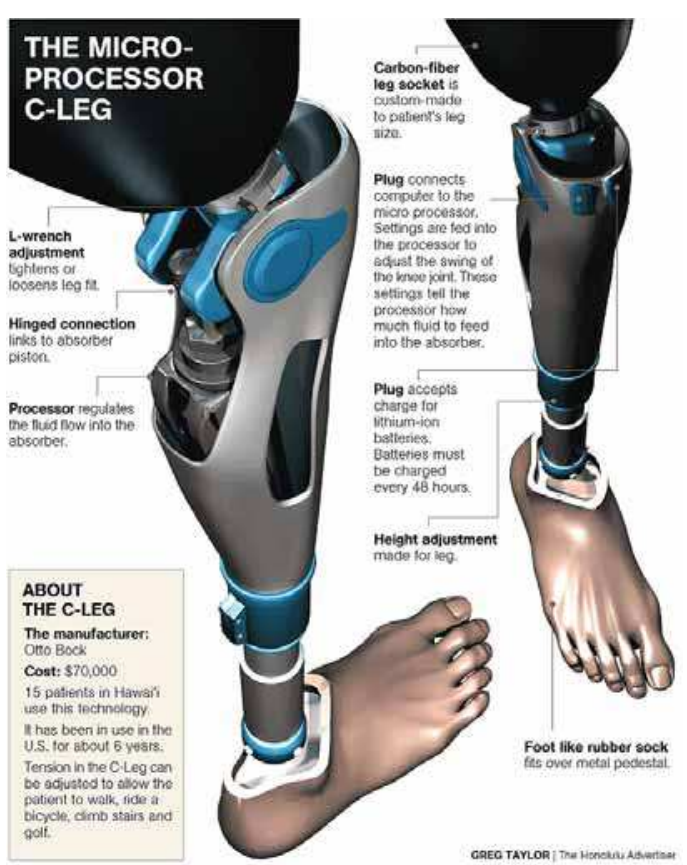

(b)

Fig. 3. Systems - (a) Engineering system (gas turbine engine) (b) Biological-Engineering system (artificial leg). 


\subsection{Health monitoring, diagnostics and prognostics (HMDP)}

\subsubsection{Health monitoring (HM)}

A health monitoring system is a framework that enables the monitoring and reporting on the state or events of a particular system. Events are detected through a network of sensors. Detected events are logged or registered within the system in an event logger. These events could either be evaluated in the event logger or transmitted for evaluation. Outcome of the evaluation is transmitted through a notification process to systems with decision making capability for action and intervention. Figure 4 illustrates a framework for remote patient and structural health monitoring. This framework goes beyond the monitoring and reporting function and presents the full cycle of health monitoring and prevention process for any system including biological, engineering or bio-engineering systems. Health monitoring is further defined as an approach to evaluating errors in or collecting general information about a system. In general, the approach presented in Figure 4 uses event classification that identifies events to a provider in order to intervene with appropriate actions.

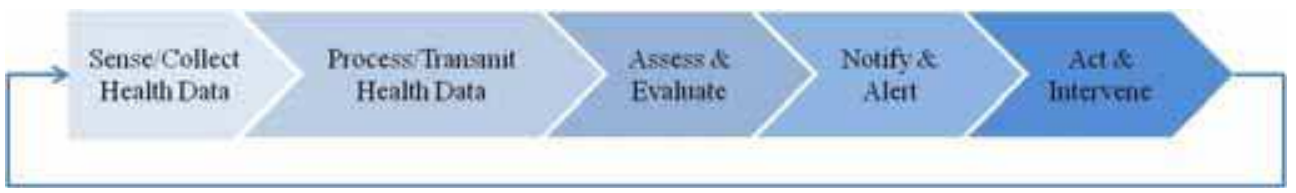

Fig. 4. A framework for remote patient and structural health monitoring.

\subsubsection{Health diagnostics (HD)}

Diagnostics is the branch of medical science that deals with diagnosis [13]. Diagnosis can be defined as the nature of a disease [14]; the identification of an illness or a conclusion or decision reached by diagnosis. To the Greeks, a diagnosis meant specifically a "discrimination, a distinguishing, or a discerning between two possibilities." Today, in medicine, that corresponds more closely to a differential diagnosis. The latter is defined as the process of weighing the probability of one disease versus that of other diseases possibly accounting for a patient's illnesses. In structural engineering, diagnostics can be defined as the nature of a structural damage (e.g. impact, corrosion, fatigue); the identification of the degree of damage or a conclusion or decision reached by the diagnosis for future action. Figure 5, illustrates a diagnosis system framework applicable to all systems including biological, engineering or bio-engineering systems.

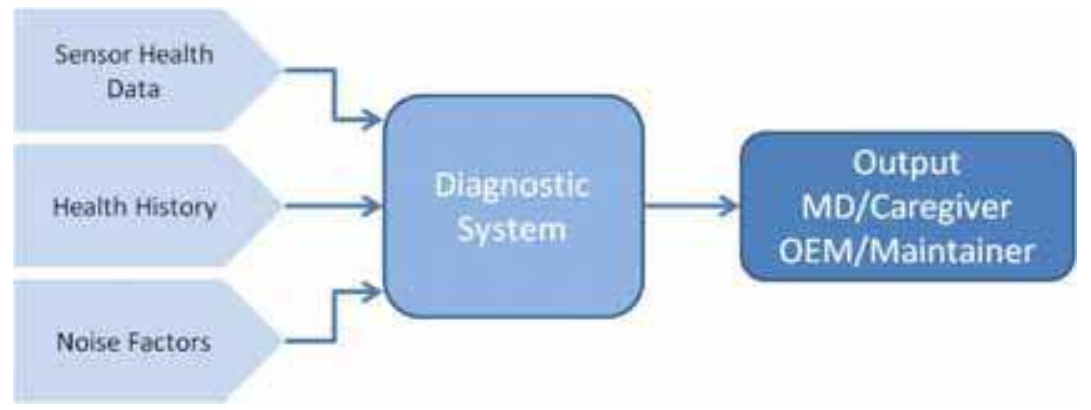

Fig. 5. A framework of a diagnostic system. 


\subsubsection{Health prognostics (HP)}

The word prognostic is taken from the Greek Prognostikos (of knowledge beforehand). It combines pro (before) and gnosis (a knowing). The word is used today to mean a foretelling of the course of a disease [14]. Prognostic is also defined as relating to prediction [15]. It is also referred to as a sign of a future happening or a sign or symptom indicating the future course of an event. In medicine as well as in engineering, it refers to any symptom or sign used in making a prognosis. Figure 6 [16] illustrates the relationship between the health monitoring, health diagnostics and prognostics, where the outcome (Remaining Useful Life (RUL)) of the prognostics module is based on the exploitation of modeling tools and sensor data.

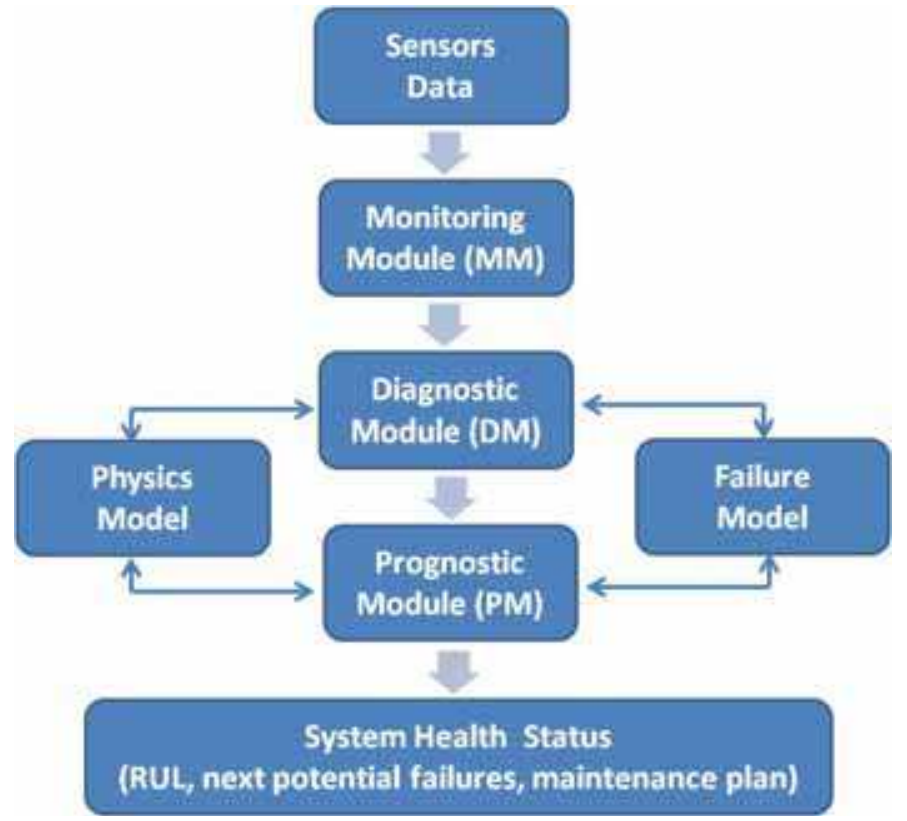

Fig. 6. A framework of a prognostics system.

At this juncture it is important to observe that the referred to terminology employed human systems and medical references as illustration platforms. It is well known that biological systems are the most complex, intelligent, expert and adaptive systems that science has encountered. It is without doubt that the evolution of our engineering systems has exploited these systems to enable the development of our current technologically-oriented, modern society. Lessons learned from bird's flight patterns and techniques have enabled more efficient, reliable and safe air travel. Understanding the evolution of sea life has provided key framework and concepts in the design of unobservable, high depth, high efficiency, selfpowered and autonomous submarines.

For bio-inspired engineering systems the terminology is to some extent altered to reflect specific systems, applications, domains, and fields; however, in recent years, several perspectives and terminology have emerged, in the engineering discipline, particularly in the field of Structural Health Monitoring (SHM) and Prognostics Heath Management (PHM) communities. The following provides the evolution on the usage of the introduced terminology. 


\subsection{Diagnostics, prognostics health management (DPHM or PHM)}

In recent years, the discipline of Diagnostics, Prognostics and Health Management (DPHM) has been formalized to address the information management and prediction requirements of operators of complex systems (e.g. aircraft, power plants, and networks) including their need for on-line health monitoring. Generally, PHM systems incorporate functions of condition monitoring, state assessment, fault or failure diagnostics, failure progression analysis, predictive diagnostics (i.e., prognostics), and maintenance or operational decision support. Ultimately, the purpose of any DPHM or PHM system is to maximize the operational efficiency, availability and safety of the target system.

As defined by Industry Canada (IC) [17], diagnostics refers to the process of determining the state of a component to perform its function(s) based on observed parameters; prognostics refers to predictive diagnostics which includes determining the remaining life or time span of proper operation of a component; and health management is the capability to make appropriate decisions about maintenance actions based on diagnostics/prognostics information, available resources, and operational demand. Figures 7 [18] provides a framework for health assessment and prognostics of electronic products as an alternative to traditional reliability prediction methods.

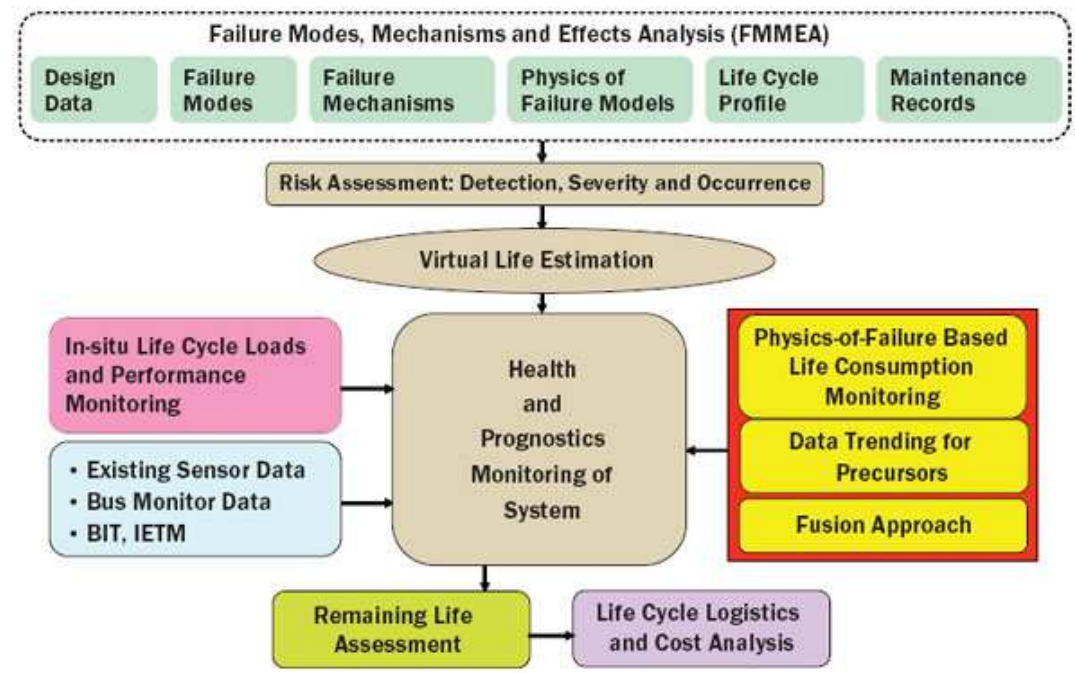

Fig. 7. A framework for health assessment and prognostics of electronic products.

\subsection{Structural health monitoring (SHM)}

SHM stands principally for structural health monitoring. It also stands for structural health management, systems health monitoring and systems health management. It must not be confused with Vehicle Health Monitoring or Management (VHM) which includes propulsion and avionics systems. Moreover, Structural Damage Sensing (SDS) is also referred to as SHM. Structural Health Monitoring (SHM) capability is a life cycle management capability that aims at providing, at every moment during the life cycle of a structure, the health state of the structure and its constituent materials. In the aerospace industry, for the structure to be airworthy, its health state must remain in the domain specified in the design, even though the structure may experience some structural degradation due to normal usage, environmental exposure, and accidental events. 
As described by Farrar and Worden [19], the SHM process involves the observation of a system over time using periodically sampled dynamic response measurements from an array of sensors, the extraction of damage-sensitive features from these measurements, and the statistical analysis of these features to determine the current state of a system's health. For long term SHM, the output of this process is periodically updated information regarding the ability of the structure to perform its intended function in light of the inevitable aging and degradation resulting from normal usage and operational environments. In the event of excessive loading, SHM is used for rapid condition screening and aims to provide, in nearreal-time, reliable information regarding the structural integrity of the structure.

Farrar and Wordon [19] defined SHM as the process of implementing a damage detection and characterization strategy for engineering structures. In this definition, damage is identified as changes to the material and/ or geometric properties of a structural system, including changes to the boundary conditions and system connectivity, which adversely affect the system's performance. Figure 8 [20] represent the link between diagnostics, prognostics and structural health monitoring and the process of implementing that framew ork. Such framework is an extension of the framework presented in Figure 6.

\subsection{Condition based maintenance (CBM and CBM+)}

Condition Based Maintenance (CBM) is a maintenance technique closely related to PHM that involves monitoring machine condition and predicting machine failure; whereas, Condition Based Maintenance Plus (CBM+) is built upon the concept of CBM, but is enhanced by reliability analysis. The US Air Force (USAF) defined CBM as a set of maintenance processes and capabilities derived from real-time assessment of weapon systems' condition obtained from embedded sensors and/or external tests and measurements using portable equipment. Whereas, CBM+ expands upon these basic concepts, encompassing other technologies, processes, and procedures that enable improved maintenance and logistics practices [21].

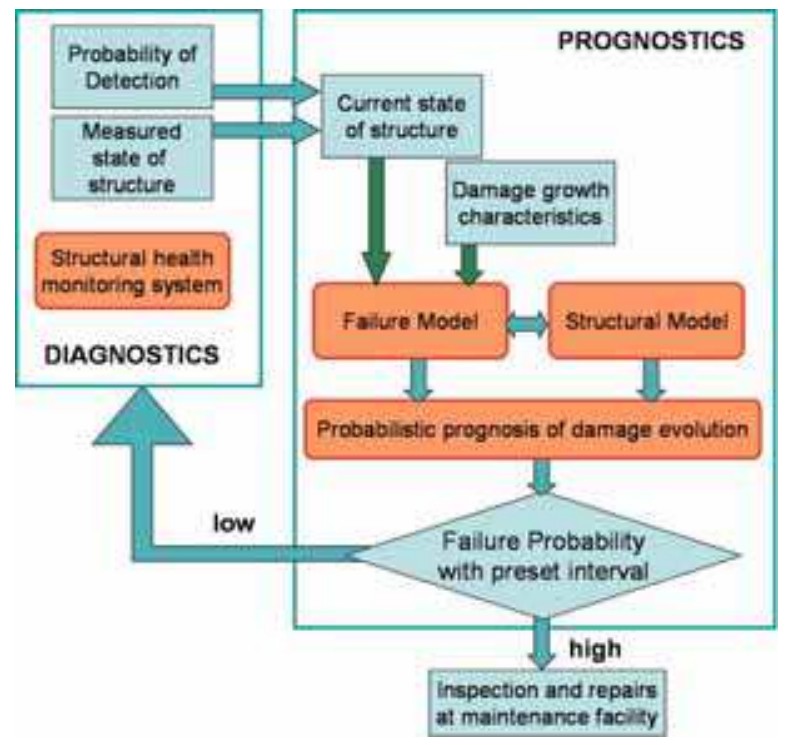

Fig. 8. A framew ork for diagnostics, prognostics and health monitoring. 


\subsection{Health and usage monitoring (HUMS)}

Health and Usage Monitoring Systems (HUMS) were developed over 30 years ago in reaction to a concern over the airworthiness of helicopters. The purpose of HUMS is to increase safety and reliability, as well as to reduce operating costs, by providing critical component diagnosis and prognosis. Unlike Structural Health Monitoring (SHM) systems or Integrated Vehicles Health Management (IVHM) that have been developed for fixed-wing aircraft, HUMS effort focused on rotorcraft, which benefit from a system's ability to record engine and gearbox performance and provide rotor track and balance. HUMS could also be configured to monitor auxiliary power unit usage and exceedances, and include built-in test and Flight Data Recording (FDR) functions.

Overall, a full HUMS is expected to acquire, analyze, communicate and store data gathered from sensors and accelerometers that monitor the essential components for safe flight. The analyzed data allows operators to target pilot training, establish a Flight Operations and Quality Assurance (FOQA) program, in which they can determine trends in aircraft operations and component usage and provide valuable date for new engine design and certification. Figure 9 [22] shows a systematic process used to successfully identify the crack length during a test of a helicopter transmission with the crack in the planetary carrier plate using vibration signals.

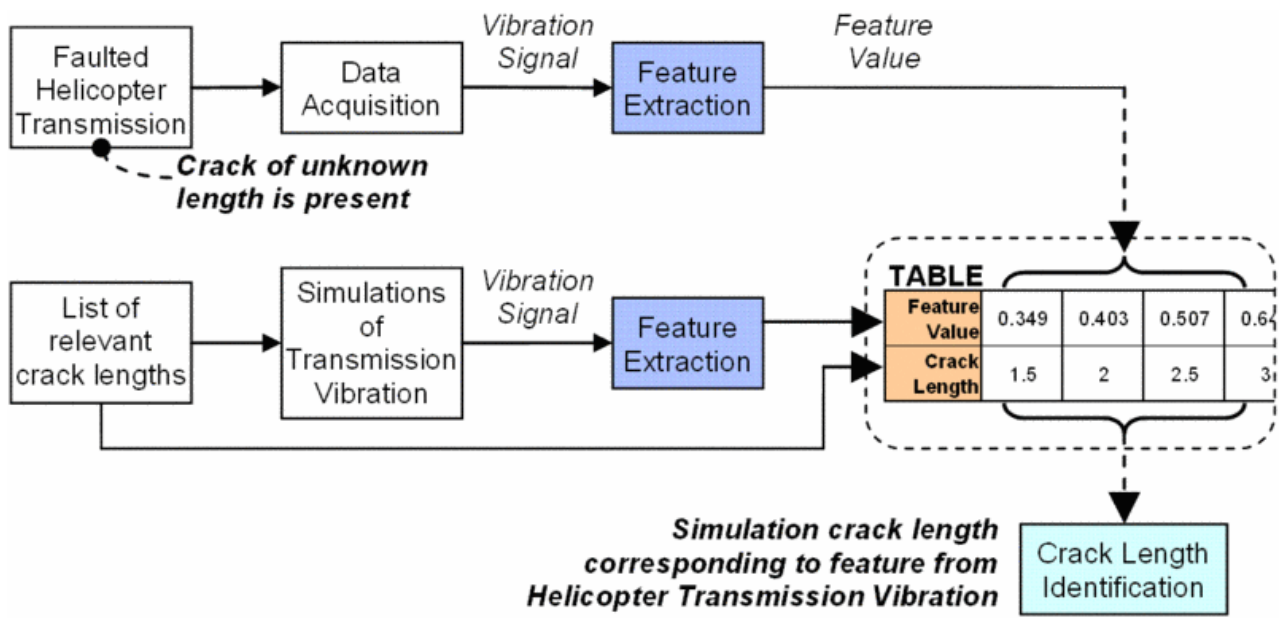

Fig. 9. A process for the identification crack length on a helicopter transmission using vibration measurements.

The terminology provided in both sections 1 and 2 , is adhered to by professionals and experts in the corresponding fields; however, within the research communities this terminology is loosely used to reflect the same concept or framework. For instance, when a new vibration sensor is employed to merely provide vibration readings, it is often referred to as a PHM vibration sensor, by engine researchers, and as an SHM vibration sensor, by the structural researchers.

\section{Systems development and implementation}

Critical infrastructure, such as dams, bridges, nuclear power plants, are currently being monitored and managed using more reliable and advanced sensors networks, diagnostics 
tools, and advanced predictive/ prognostics capabilities, presented in the terminology section. Infrastructure managers and maintainers are now able to obtain the health state of the infrastructure remotely and in a timely fashion through the deployment of wireless capability. Such advanced information, facilitates reliable and efficient maintenance planning and infrastructure upgrades and acquisition and even contribute to future systems design. Additionally, and in recent years, the aerospace sector has significantly intensified its efforts in the development, exploration, qualification and certification of some autonomous systems. Current emerging platforms, such as the Joint Strike Fighter (JSF), possesses integrated autonomic logistic capability that is based on a PHM system, for increased platform safety, reliability, availability, reduced life cycle cost, and enhanced logistics. The deployment of an autonomic logistic capability is expected to reduce the platform life cycle cost by as much as $20 \%$. It has also been reported that even though the platform employs the latest technology and concepts several components of the PHM system employ traditional sensors. However, the next generation fighter could benefit from the continuous evolvement of SHM and PHM concepts, frameworks, and technologies.

Independent of the simplicity or complexity of the system architecture, four building blocks are required to constitute the core of DPHM systems' architecture and structure. These blocks are: sensor networks, usage and damage monitoring (diagnostics), life management (predictive and prognostics), and decision making and asset management. A possible approach to describing the functioning of such a system is that usage and damage parameters, acquired via wired and wireless sensors network, are transmitted to an onboard data acquisition and signal processing system. The acquired data is developed into information related to damage, environmental and operational histories as well as system usage employing information processing algorithms embedded into the usage and damage monitoring block. This information, when provided to the life management block and through the use of predictive diagnostic and prognostics models, is converted into knowledge about the state of operation and health of the system. This knowledge is then disseminated and transmitted to the crew, operations and maintenance services, regulatory agencies, and or Original Equipment Manufacturers (OEM) for decision making and assets management.

Analogous to a biological system, and as shown in Figure 10, the nervous system constitutes the critical and perhaps the most significant and limiting factor in the development and implementation of DPHM systems. Sensors and sensor networks must be accurate, reliable, robust, small size, lightweight, immune to radio frequency and electromagnetic interferences, easily networked to on-board processing capabilities, able of withstanding operational and environmental conditions, requiring no or low power for both passive and active technologies and possess self-monitoring and self-calibrating capabilities. In the engineering community, this "nervous system" is referred to as advanced or smart sensors network. It has the potential to perform several functions delivered by Nondestructive Evaluation (NDE) techniques in a real-time on-line environment with added integrated capabilities, such as signal acquisition, processing, analysis and transmission. These highly networked sensors (passive or active) are suitable for large and complex platforms and wide area monitoring and exploit recent development in micro and nano technologies. These sensors include Microelectromechanical systems (MEMS) sensors [23], fiber optic sensors 
[24], piezoelectric sensors [25], piezoelectric wafer active sensor [26], triboluminescent sensors [27], Stanford Multi-Actuator-Receiver Transduction (SMART) layer sensor networks [28], nitinol fiber sensors [29], carbon nanotube sensors [30], and comparative vacuum sensors [31]. In the following sections only selected emerging sensors and sensor concepts, with potential for advancing aircraft DPHM, are presented.

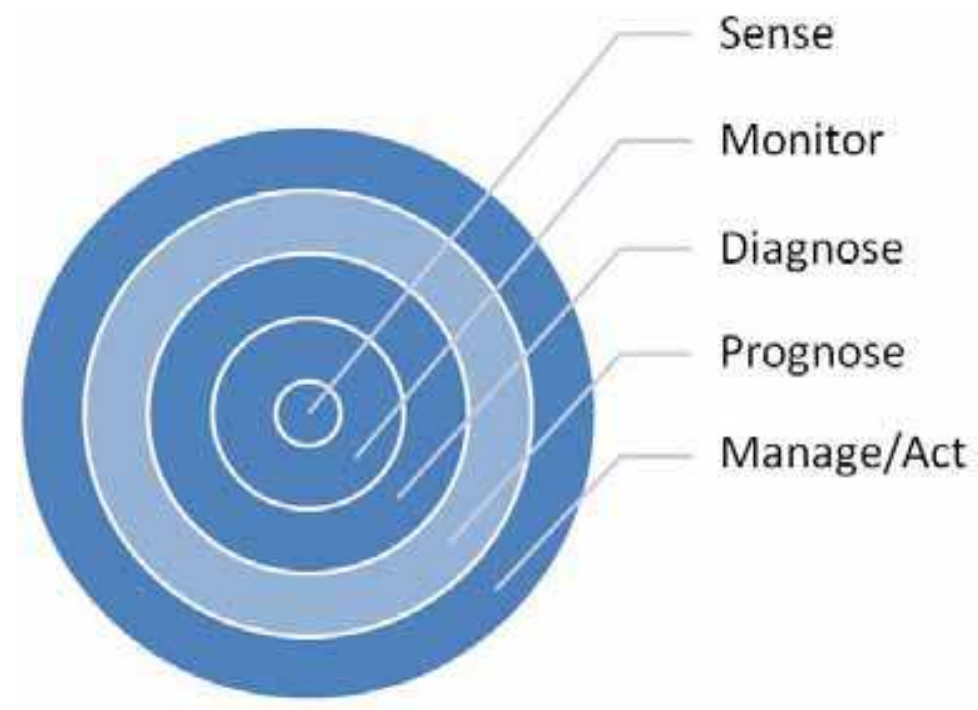

Fig. 10. Core functions of a DPHM or a Biological System (the Prognosis function does not exist for a biological system)

\subsection{CNT-based sensors}

Carbon nanotubes (CNT) are piezoresistive in nature, i.e. these materials exhibit a change in electrical resistance as a result of change in mechanical strain or deformation. Such characteristics are now used to develop CNT-based strain sensors for potential integration into a DPHM system. Four types of CNT-based films, fibers and structures have successfully been evaluated for this purpose including CNT film ("buckypaper"), CNT-modified polymers, Layer-By-Layer (LBL) assembly of CNT and CNT-fibers.

\subsubsection{CNT-based film strain sensor (Buckypaper sensor)}

Dharap et al. [32] were the first to use buckypaper films as strain sensors. Figure 11 illustrates the linear response of a buckypaper film attached to a brass tensile sample. Vemuru et al. [33] have improved the buckypaper strain sensor range (500 $\mu \varepsilon)$ by using Multi-Walled CNT (MWCNT). They have observed a sensitivity of 0.4 and a linear sensor response up to a strain of $1000 \mu \varepsilon$. In their work they highlighted that the piezoresistive behavior of the CNT-network is not only dependant on the change of the film dimension under strain but about $75 \%$ of the change in resistance is due to the characteristics of the CNT network itself. In another related work, a carbon nanotube/ polycarbonate thin film was used as a strain sensor, resulting in measurement sensitivity of 3.5 times higher than that of a traditional strain gauge [34]. 


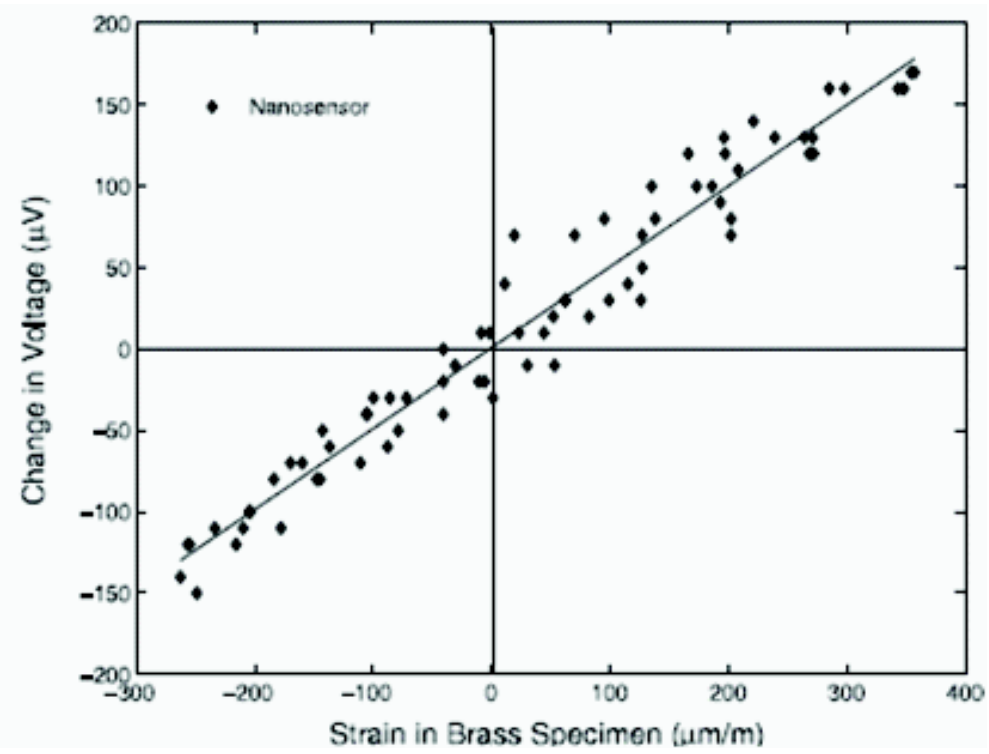

Fig. 11. Linear response of a buckypaper attached to a brass tensile sample.

\subsubsection{CNT-based film strain sensor (CNT-modified polymer (SWCNT-PMMA))}

Kang et al. [35] have used Single Walled CNT (SWCNT) modified PMMA (polymethyl methacrylate) to manufacture CNT-based strain sensors. Using different weight fraction of SWCNT, they were able to tune the guage factor and resistivity of the strain sensor, as shown in Figure 12. It has been observed that some of the benefits provided by this sensor type include increased dynamic range performance and increased linear strain range. For instance the SWCNT-PMMA sensors can withstand strains of up to $1500 \mu \varepsilon$; whereas buckypaper can withstand strains of up to $500 \mu \varepsilon$.
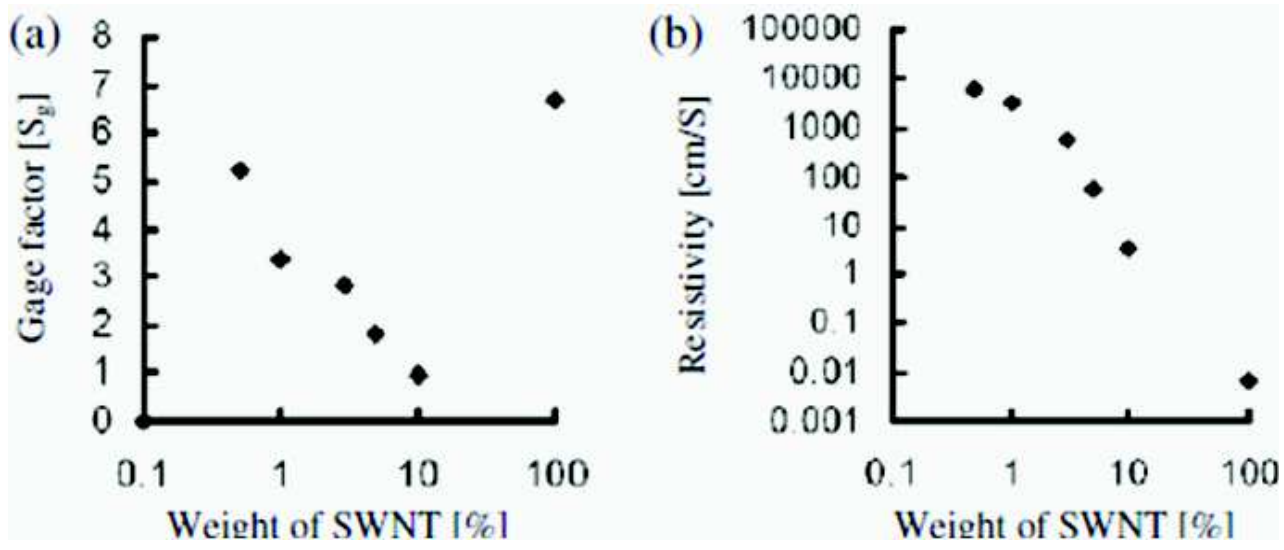

Fig. 12. Gage factor (a) and resistivity of PMMA nanocomposite with different weight fraction of SWCNT. 


\subsubsection{CNT-based film strain sensor (CNT-modified polymer (LBL assembly, CNT- PDMS))}

Unlike Buckypaper sensors and SWCNT-PMMA sensors, composite Layer-By-Layer (LBL) assembly strain sensors, demonstrated lower sensitivity (e.g. one-seventh that of Buckypaper sensor sensitivity [35]) and increased linear strain range of up to $10000 \mu \varepsilon$; as opposed to the aforementioned (e.g. SWCNT-PMMA sensors $(1500 \mu \varepsilon)$, Buckypaper (500 $\mu \varepsilon)$. To further improve the sensor performance, increase the mechanical robustness, and enhance the linear strain range $(45000 \mu \varepsilon)$, Song et al. [36] used a polymer thin film based on polydimethylsiloxane (PDMS). Figure 13 illustrates the linear behavior (up to $0.45 \%$ of strain) of the hybrid CNT-PDMS films manufactured through LBL assembly with different concentrations of CNT.

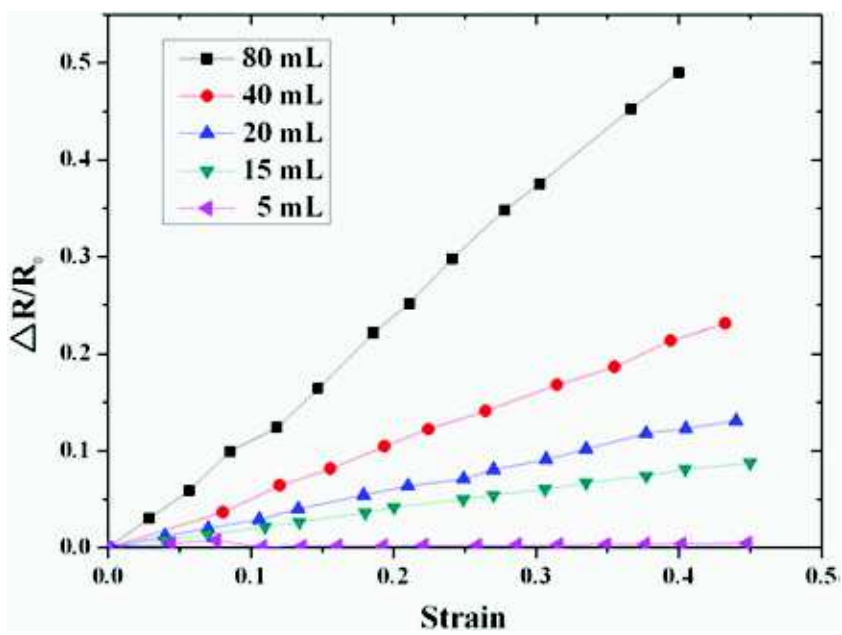

Fig. 13. Sensitivity of CNT-based polymer thin film sensor based on polydimethylsiloxane with different content of CNT.

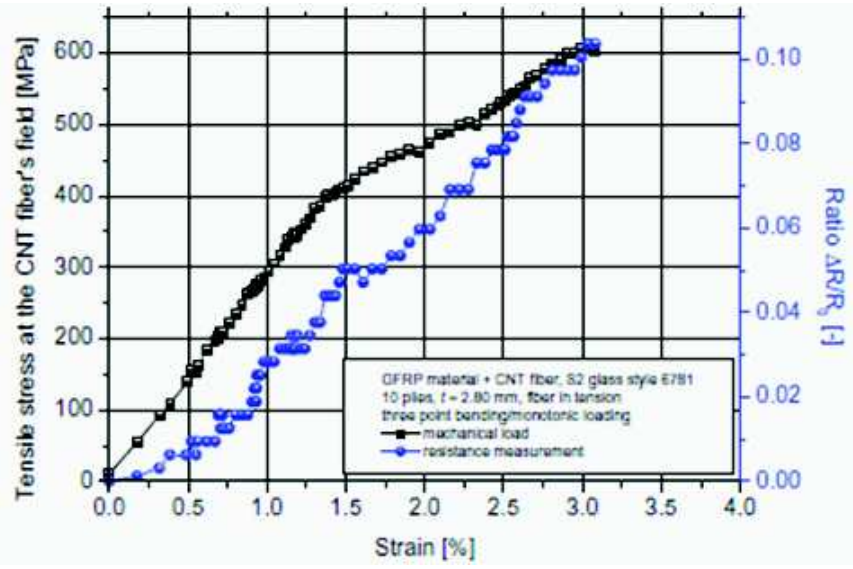

Fig. 14. Correlation between tensile stress of a glass fiber laminate composites and resistance change within an embedded CNT fiber. 


\subsubsection{CNT-based fiber strain sensor}

In their communications, Thostenson and Chou [37], Alexopoulos et al. [36] used embedded CNT fibers for strain sensing as well as damage monitoring of glass fiber composites. Their correlation of the resistance change of the embedded fiber and tensile stress (equivalently the tensile strain) of the laminate composite is illustrated in Figure 14.

It is clear that CNT-based sensors provide selectivity, flexibility, and tailored sensor sensitivity and strain range. The latter, is provided by changing of manufacturing process or approach, varying CNT content, and host polymer matrix. Even though these sensor types suffer from lower technology readiness levels, they offer the potential of multifunctional capability and flexibility of instrumentation. Our current efforts and contributions to the development of such sensor capability for DPHM can be seen in [38]. Figure 15 [39], illustrates the results of our current CNT-based crack detection sensor design, where it is illustrated that CNT current output changes in function of number of loading cycle and crack growth.

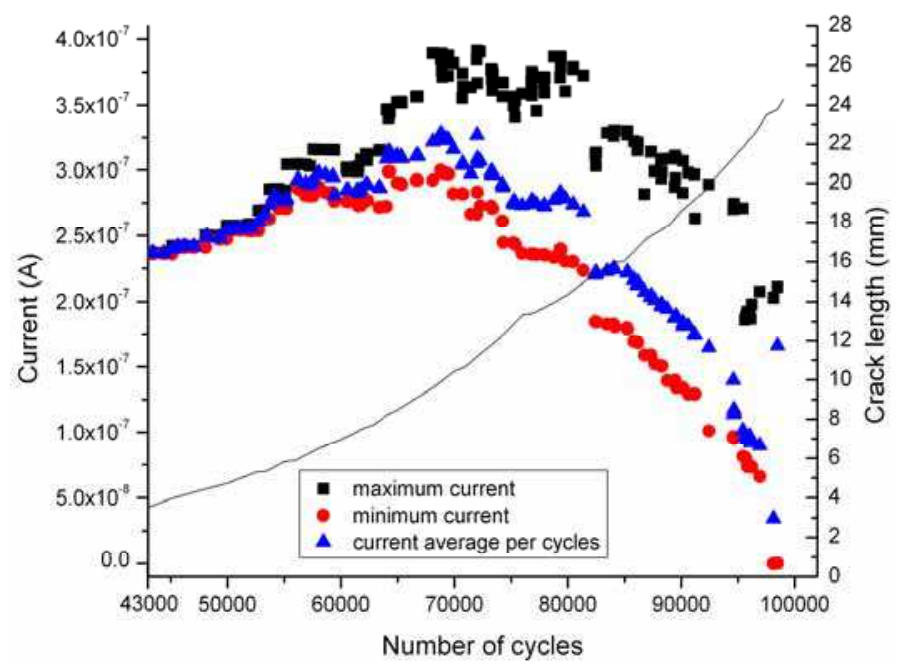

Fig. 15. Crack growth monitoring using CNT-based sensor.

\subsection{MEMS-based sensors}

Microelectromechanical systems or devices (MEMS) are referred to as smart or advanced devices. A smart device is defined as one that operates using computers [40] (e.g. smart cards); whereas, an advanced device is said to be "highly developed or difficult." According to the IEEE 1451 standard [41], a smart sensor is defined as "one chip, without external components, including the sensing, interfacing, signal processing and intelligence (selftesting, self-identification or self-adaptation) functions". Figure 16 [41] illustrates the smart sensor concept as defined by IEEE 1451.

Sensors based on this smart concept generally exploit development in MEMS and nano technologies along with advanced wireless devices with radio frequency communications. Figure 17 [42] depicts such a smart sensor, known as a sensor node, for multi-parameters sensing, where Figure 17a reflects the original prototype and Figure $17 \mathrm{~b}$ represents the commercial final node. In this case, the sensor node contains four major components: 3M's MicroflexTM tape carrier, thinned MEMS strain sensors, Linear Polarization Resistor (LPR) sensors to detect wetness and corrosion and electronics module. The electronics module is 
composed of a Micro Controller Unit (MCU), a signal conditioning unit, a wireless Integrated Circuit (IC) unit, a battery and an antenna. Employing this node design, Niblock et al. [43] developed an Arrayed Multiple Sensor Networks (AMSN) for materials and structural prognostics.

Some of the observed benefits employing smart sensors systems include the wealth of information that can be gathered from the process leading to reduced downtime and improved quality; increased distributed intelligence leading to complete knowledge of a system, subsystem, or component's state of awareness and health for 'optimal' decision making. Additionally, due to their significant small size and integrated structure, these sensors can potentially be embedded into composites structures or sandwiched between metallic components for remote wireless and internet based monitoring. Intelligent signal processing and decision making protocols can also be implemented within the node structure to provide ready to use decisions for reduced downtime and increased maintenance efficiency.

Due to significant potential of MEMS-based sensors and driven by the requirement for the development of advanced SHM and engine PHM capability, our current efforts focused on the development, characterization and demonstration of MEMS-based humidity sensors in anticipation of further development of engine condition monitoring sensors, including sensors that monitor the state of combustion and level of pollution, such as monitoring Nitric Oxide (NO), Carbon Monoxide (CO), Carbon Dioxide $\left(\mathrm{CO}_{2}\right)$ and Oxygen $\left(\mathrm{O}_{2}\right)$.

Figure 18 [44] presents measurement results for a MEMS-based humidity sensor, which is comprised of the sensor, the integrated circuit (IC) interface and the printed circuit board (PCB). This sensor is based on a capacitor with a moisture sensitive dielectric material. Results show how the capacitance of the sensor varies with relative humidity over the range of $11 \%$ to $97 \%$ and illustrates how this development allows for accurate measurements without extensive (and costly) calibration schemes.

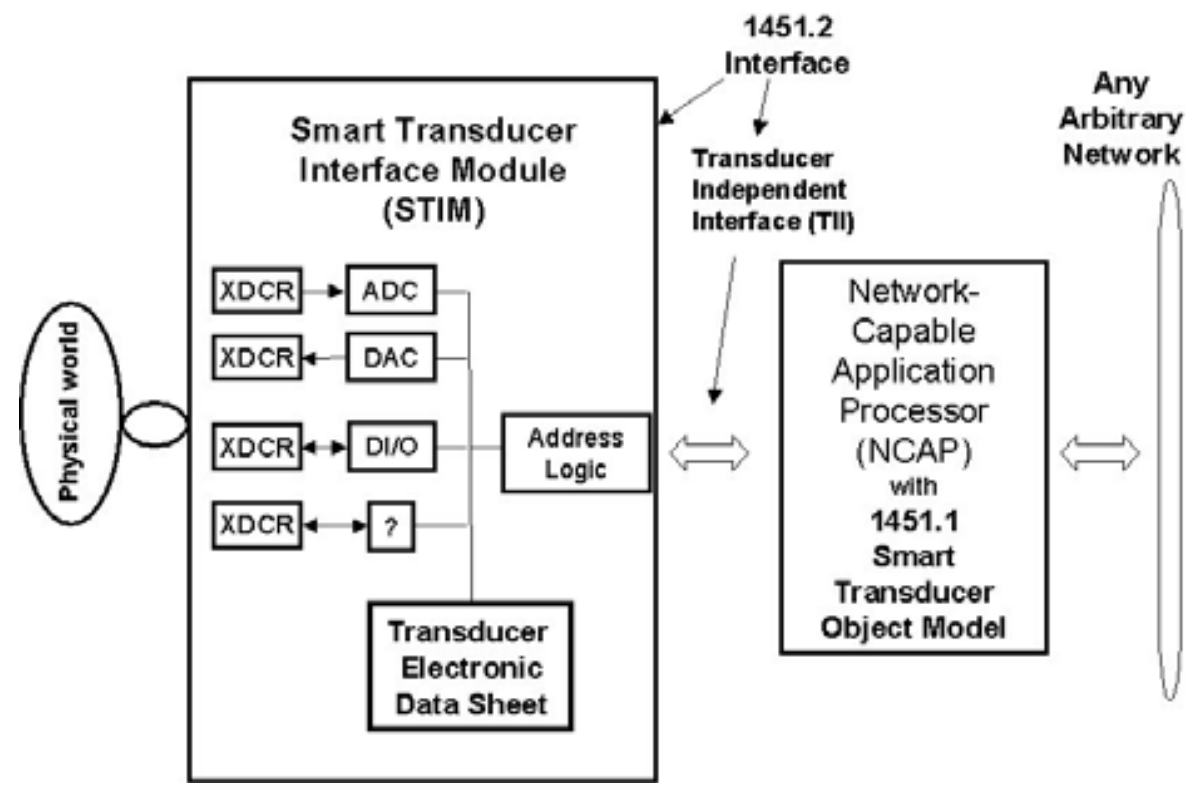

Fig. 16. Smart sensor concept defined by IEEE 1451. 


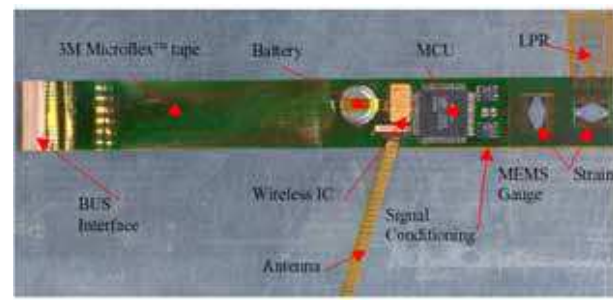

(a)

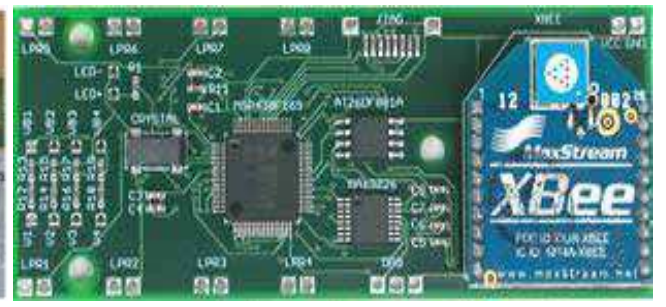

(b)

Fig. 17. Smart MEMS based smart sensor node.
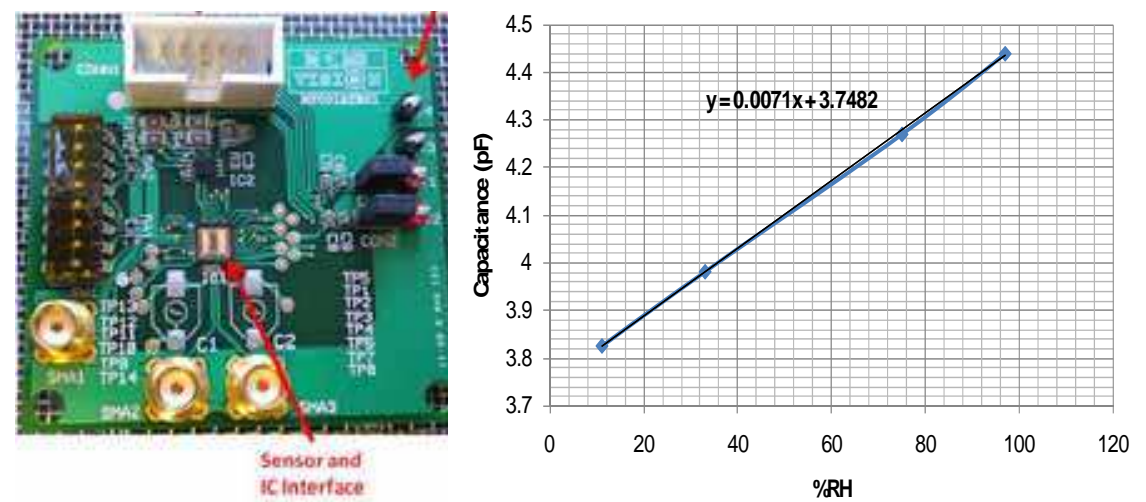

Fig. 18. MEMS based relative humidity sensor node.

\subsection{RFID-based sensors}

The use of Radiofrequency Identification (RFID) technology dates back to World War II. This technology has and continues to revolutionize the supply chain and assets management. Wal-Mart, FedEx and UPS are examples of the early adopters of the technology [45]. This technology is posed to continue to benefit both military and commercial sectors particularly in the field of focused logistics. The emergence of the DPHM concept and the requirement for autonomous wireless sensor networks has intensified efforts in integrating sensor capability within these identification devices. Current RFIDbased sensors can be used for the monitoring of temperatures, chemicals, strains and humidity. Ong et. al. [46] demonstrated the use of inductive-based coupling RFID technology, at a frequency of $22.5 \mathrm{MHz}$, to detect temperature and humidity. Figure 19 illustrates the frequency-temperature relationship for temperatures ranging from $0^{\circ} \mathrm{C}$ to $110^{\circ} \mathrm{C}$. A sensitivity of $6.4 \mathrm{kHz} /{ }^{\circ} \mathrm{C}$ was demonstrated.

Our current research effort mainly focused on the development of reliable autonomous, power-free RFID-based sensors for integration within a DPHM system in an aircraft environment. Figure 20, illustrates an experimental configuration for the detection of crack initiation in a metallic structure under static loading within an MTS load frame. A handheld multi-purpose MC-9000G RFID reader was used to detect the tag that constituted a component of the closed loop crack detection sensor system. The crack detection sensor was developed in house and its particulars can be found in [47]. Additionally, using backscattering-based RFID technology, at frequency of $915 \mathrm{MHz}$, we demonstrated 
temperature and humidity measurements, using RFID tag characteristic variation, such as changes in resonant frequency (phase and magnitude) and impedance. Figure 21, illustrates the frequency-temperature and humidity relationship for temperatures up $100^{\circ} \mathrm{C}$. An average temperature sensitivity of $71.3 \mathrm{kHz} /{ }^{\circ} \mathrm{C}$ and $0.725 \mathrm{MHz} / \% \mathrm{RH}$ were demonstrated, respectively for temperature and humidity.

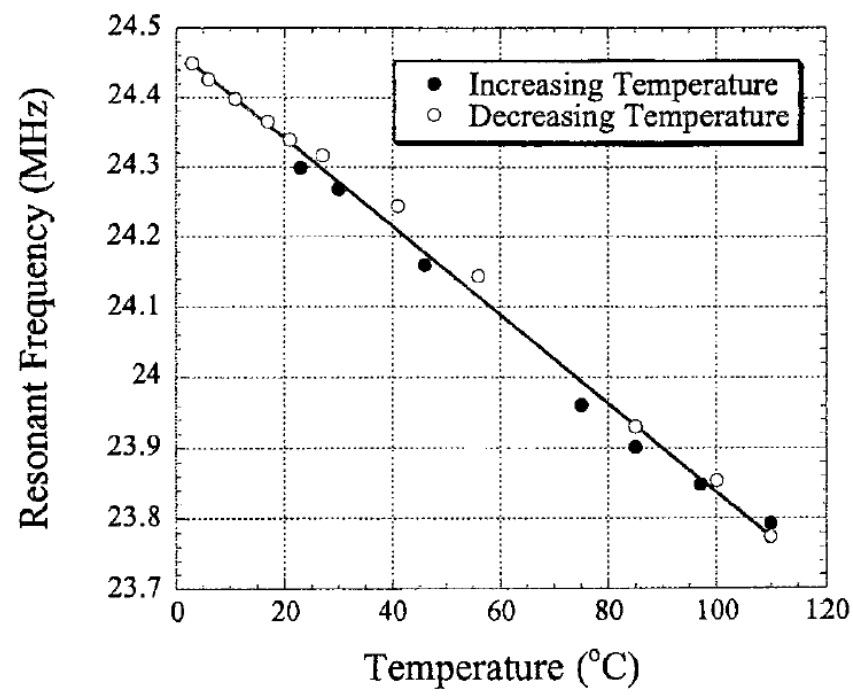

Fig. 19. Frequency-temperature relationship for $22.5 \mathrm{MHz}$ resonant frequency.

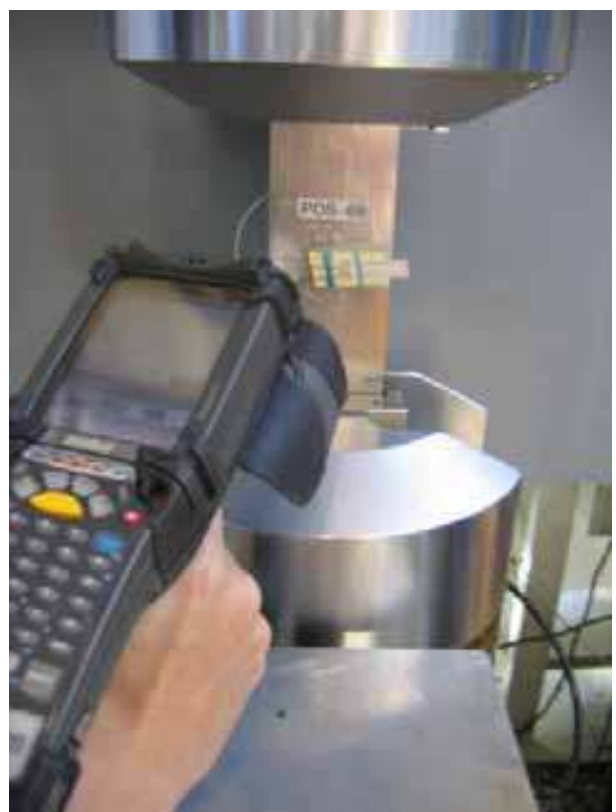

Fig. 20. Ilustration of an RFID-based crack detection approach. 


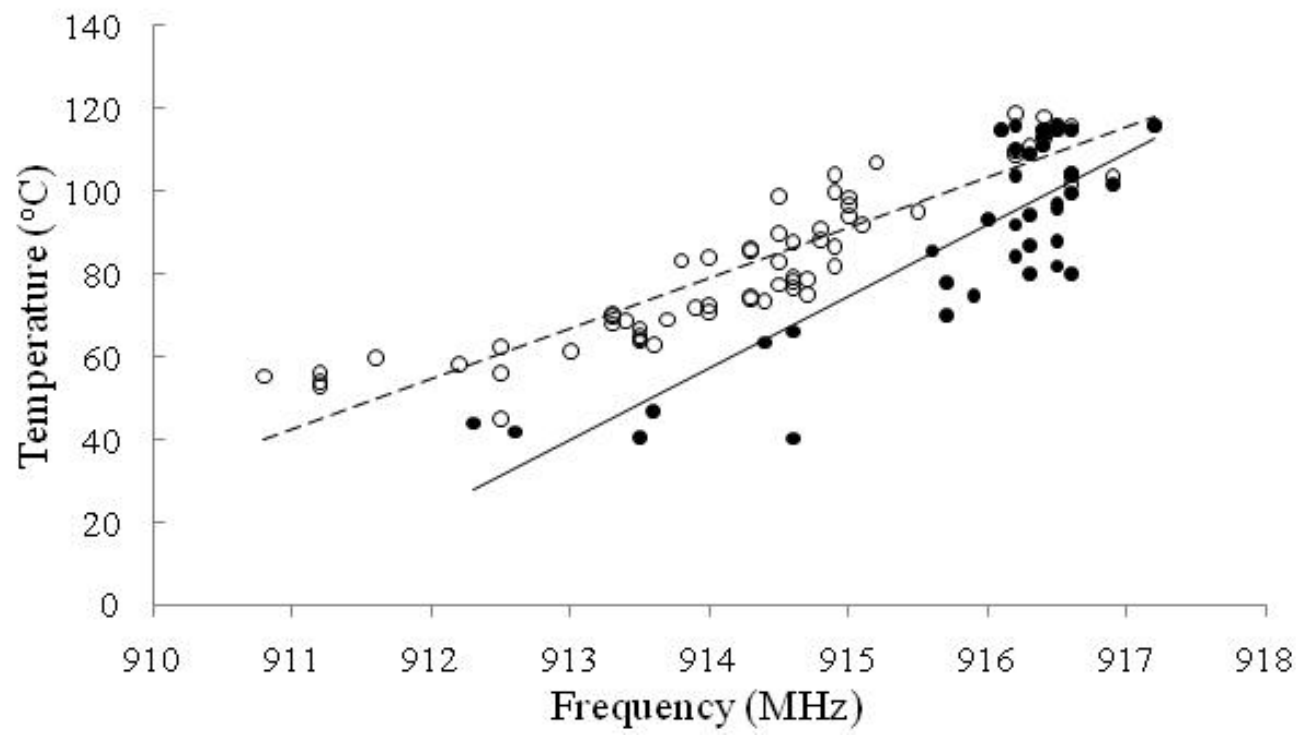

(a)

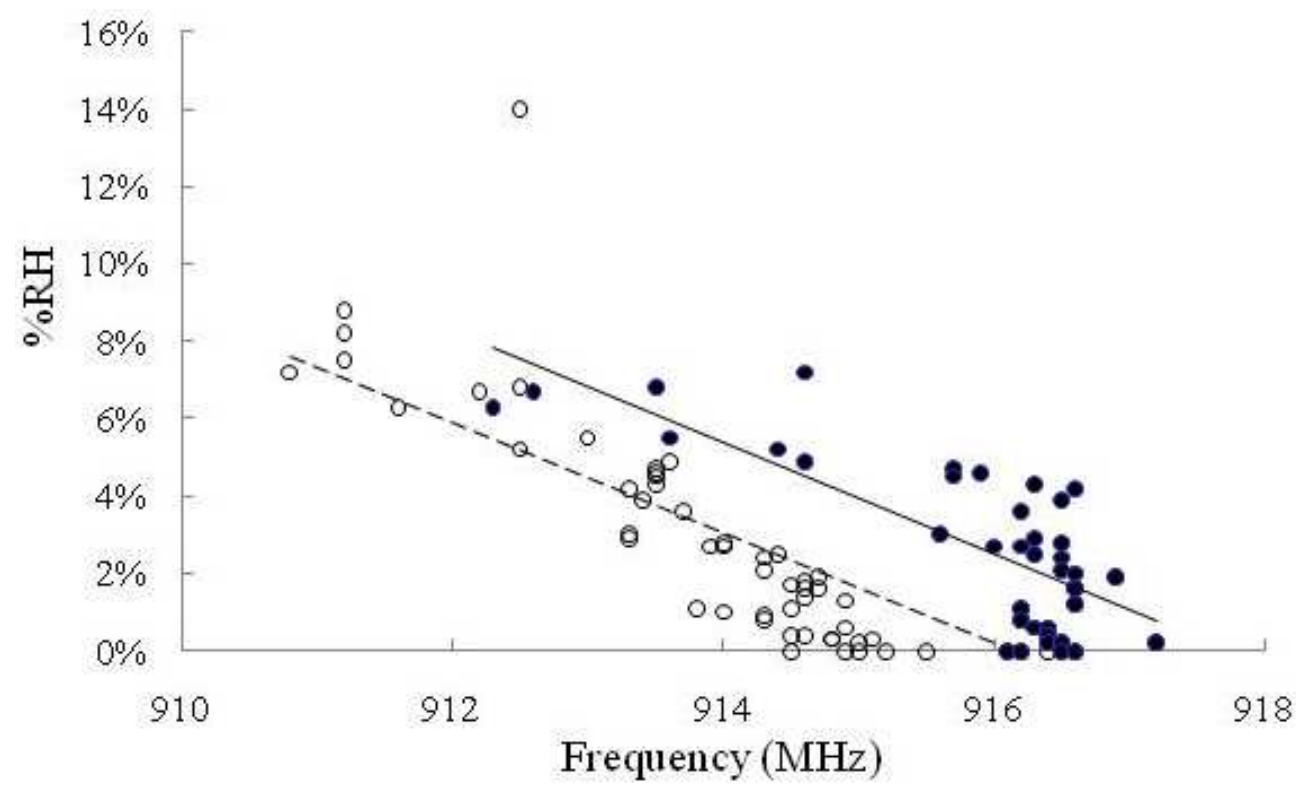

(b)

Fig. 21. Frequency-temperature (a) and Humidity (b) relationship for $915 \mathrm{MHz}$ resonant frequency. 
It is noted through our research (not shown here) that High Frequency (HF) inductive-based coupling RFID possesses good immunity to environmental effects and provide limited detection range. Whereas, Ultra High Frequency (UHF) backscattering based RFID possesses an increased detection range with reduced signal-to-noise ratio (SNR). Both HF and UHF provided similar performance for the parameters under consideration (e.g. humidity and temperature).

\subsection{Emerging health monitoring sensor systems}

This document has so far provided a perspective on the role of biological functions and characteristics in engineering innovation and the development of DPHM related concepts and frameworks. The above briefly presented sensors and sensor concepts have mainly focused on the concept of advancing autonomous sensor networks for potential integration into a health monitoring and management capability. In the following sub-sections a very brief introduction to the main two SHM capabilities (Piezo- and fiber optic-based) that has seen significant development and demonstration within the aerospace sector. It is noted that even though these systems have a high Technology Readiness Level (TRL), their implementation within the commercial or military sectors continue to be limited due to several challenges including size, weight, power requirements and excessive cabling; hence the discussion of Section 3. The reader is encouraged to consult [48] for more details on these systems and other ones.

\subsubsection{Piezoelectric (PZT)- based sensor networks}

Piezoelectric material can be used both for active and passive defect detection employing a network of sensors. As illustrated in Figure 22 [49], in the active mode, an electric pulse is sent to a piezoelectric actuator that produces Lamb waves within the structure under evaluation. The array of piezoelectric sensors will pick up the resultant Lamb waves for processing and analysis. If defects, such as cracks, delamination, disbond or corrosion, exist within the range of sensors array, a change in the reference "healthy" signal results. These systems rely on a reference signal in the structure before they are placed in service. The location and the size of the defect can generally be determined from the degree of signal change. In the passive mode, sensors are used continuously as "listening" devices for any possible damage initiation or propagation. Sensors within the network can detect impact and defect events, including crack formation, delamination, disbond, and possibly nonvisible impact damage.

Systems based on this dual concept of passive and active monitoring have been developed [50-51] (e.g. Stanford Multi-Actuator-Receiver Transduction (SMART) Layer based system) and demonstrated. Such systems are designed and built around a set of piezoelectric sensors/ actuators networks, diagnostics software, analysis tools and graphics user interface. Figure 23 depicts a schematic of sensors/ actuators network layout. Additionally, Figure 24 illustrates the ability to detect defects using this piezo-based approach. Such Figure clearly illustrates the waves-damage interaction.

This sensor-based approach provides significant SHM potential due to its high multiplexing flexibility and suitability for harsh environment; however it suffers from excessive wiring and reduced imaging software effectiveness. Even though tremendous progress was reported in this area, significant research is still needed to bring this technology to practical deployment and to facilitate its qualification and certification. 

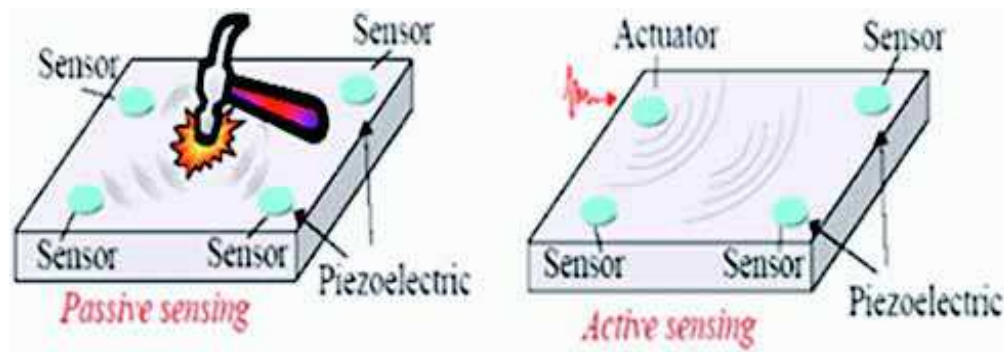

Fig. 22. Passive and active sensing mode using piezoelectric materials.
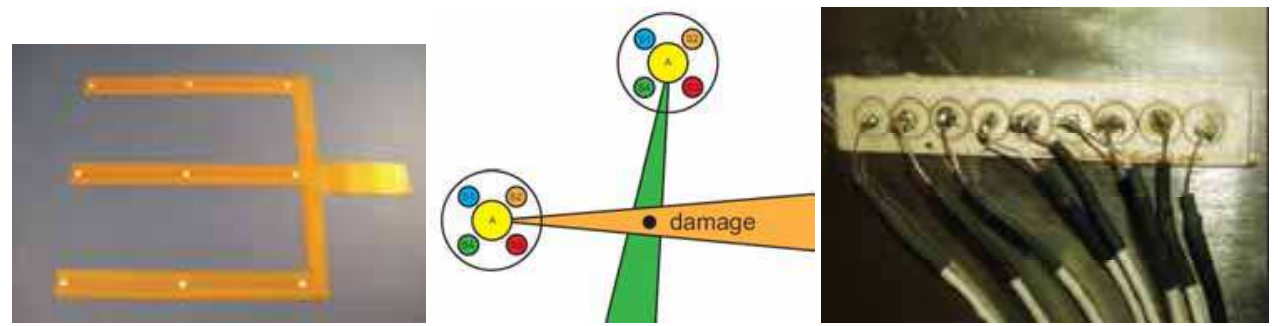

Fig. 23. Schematic of sensors/ actuators network Layout (Acellent SMART layer, Metis Design Intelliconnector \& Vector locator, and university of Sherbrooke's micro-machined PZT array).

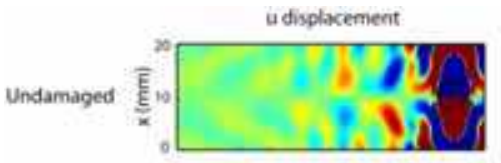

Damaged

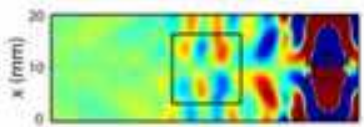

sattered

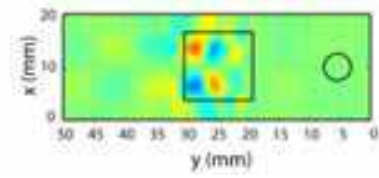

$\checkmark$ displacement
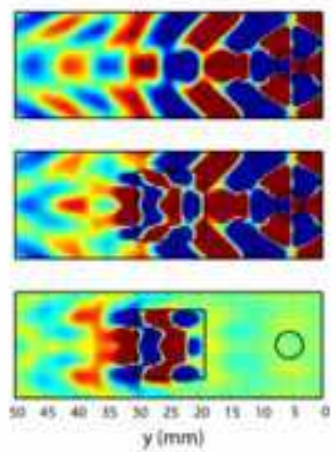

w displacement
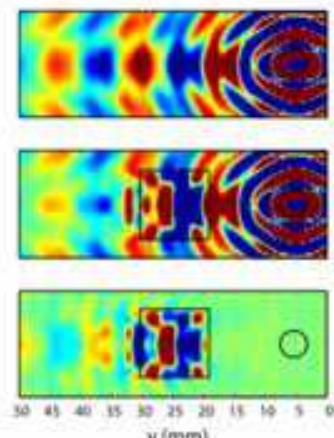

Fig. 24. Simulation results for longitudinal (u,v) and transverse (w) displacement components on the surface of a metallic structure ( undamaged case (top), damaged area (middle) and scattered field (bottom)).

\subsubsection{Fiber optic based sensor networks}

Because of their very low weight, small size, high bandwidth and immunity to electromagnetic and radio frequency interferences, fiber optic sensors have significant performance advantages over traditional sensors. Fiber optic sensors offer unique capability, such as monitoring the manufacturing process of composite and metallic parts, performing non-destructive testing once fabrication is complete, enabling structural and component 
health monitoring for prognostics health management, and structural control for component life extension. Such capability exploits optical characteristics and makes use of a variety of novel phenomena inherent in the structure of the fiber itself. Some of these phenomena are extensively discussed in the literature [52-53].

In general fiber optic sensors are classified as discrete or distributed. The distributed class of sensors includes Michelson and Mach-Zhender interferometer as well as sensors based on Brillouin scattering. These are generally seen in infrastructure applications where spatial resolution, system's weight and size are not as critical and long range sensing is desired [54]. The discrete class of sensors include cavity-based and grating-based designs. Cavity-based designs utilize an interferometric cavity in the fiber to create the sensor and define its gauge length. Extrinsic and Intrinsic Fabry-Perot interferometers (EFPI, IFPI), along with In-Line Fiber Etalon (ILFE) are the most known ones. Grating-based designs utilize a photo-induced periodicity in the fiber core refractive index to create a sensor whose reflected or transmitted wavelength is a function of the periodicity that is indicative of the parameter being measured. Any shift in the reflected wavelength indicates a change in the monitored parameter. This principle of operation of Bragg gratings based sensors is shown in Figure 25 [52].

Due to their high sensitivity, small size (40-125 $\mu \mathrm{m})$, high multiplexing capability forming highly effective sensor networks and ease of integration into structural materials, Fiber Bragg Gratings (FBG) are the most commonly used sensors for SHM applications. As shown in Figure 26 [55], these sensors can be used to monitor bondline integrity in bonded joints, acoustic emission resulting from structural damage and corrosion monitoring.
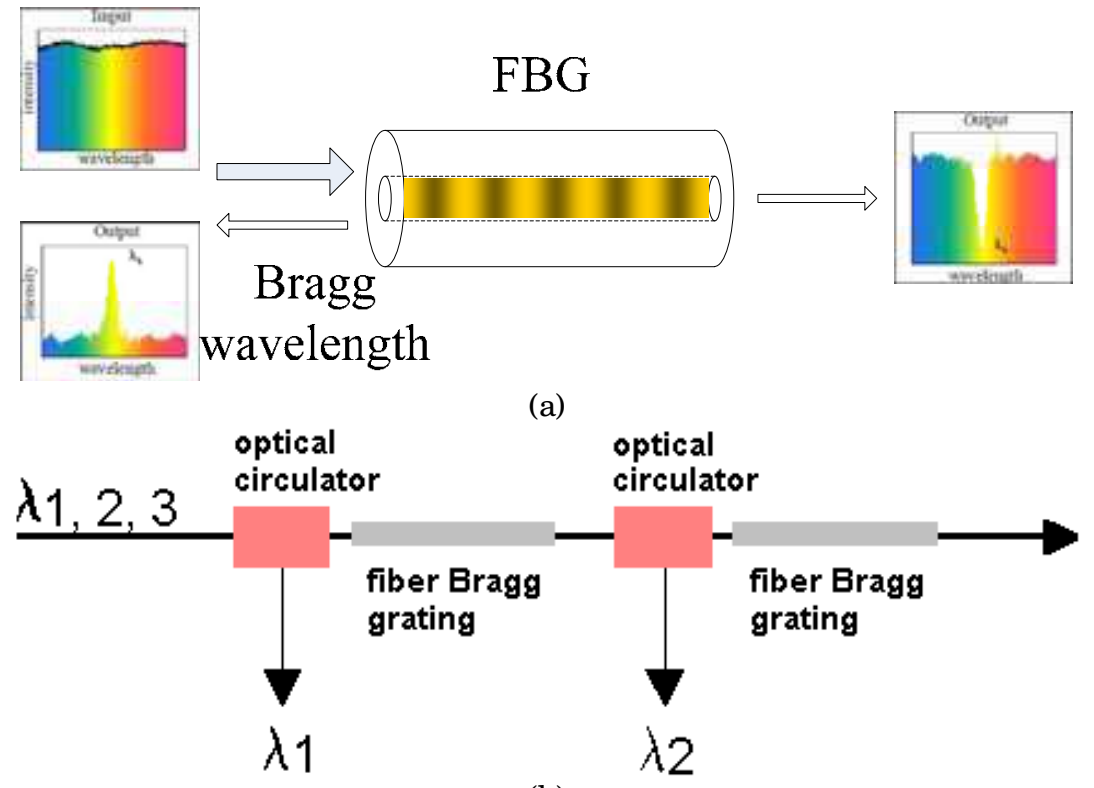

(b)

Fig. 25. Fiber Bragg gratings principle of operation for single and serially placed gratings. 

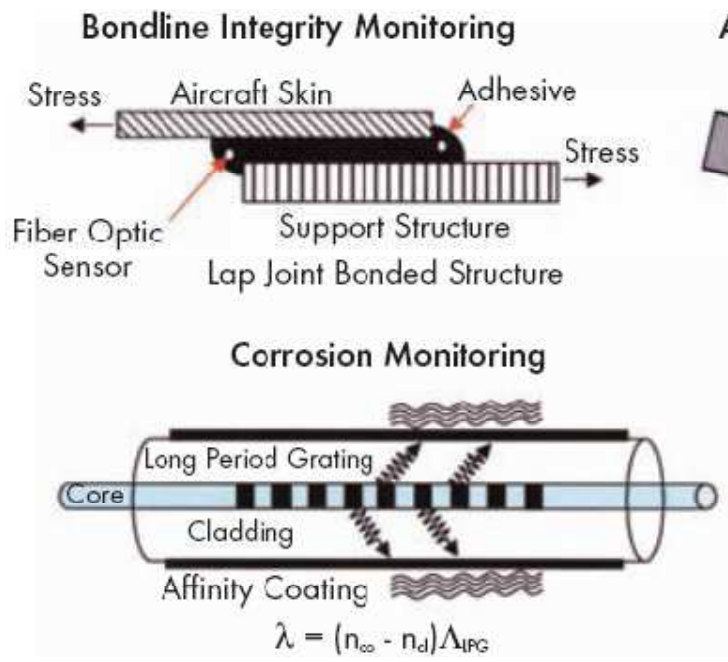

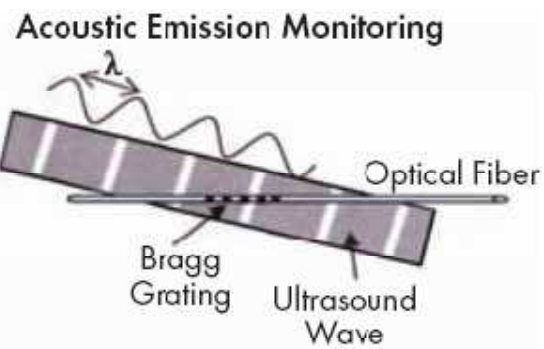

$\lambda$ Wavelength

$\mathrm{n}_{\infty} \quad$ Reflective index, core

$\mathrm{n}_{\mathrm{cl}} \quad$ Refractive index, cladding

$\Lambda_{\text {IPG }}$ Bragg Grating Period for

Long Period Grating

Fig. 26. Fiber Bragg Gratings-based sensing.

Despite the extensive and successful outcomes of several investigations supporting aerospace platform DPHM requirements, research efforts continue to address the critical issues for practical implementation that include adhesive selection, bonding procedures, and quality control for surface mounted fiber optic sensors; optimum selection of sensor configuration, sensor material and host structure for embedded configurations; characterization of embedded fiber optic sensors at elevated and cryogenic temperatures; resolution optimization for desired parameters from multi-gratings as well as sensitivity to transverse and temperature effects; development of an integrity assurance procedure for embedded sensors, particularly sensor protection at egress/ ingress points.

\section{Conclusion}

Understanding the functionality and characteristics of biological systems has significantly contributed to innovation in the engineering and medical disciplines. Engineering systems, such as systems for structural health monitoring, prognostics health management, condition based maintenance, health and usage monitoring, and life cycle management, have exploited such knowledge to develop bio-inspired system functionalities. This document provided a perspective on the role of biological functions and characteristics in engineering innovation. It introduced systems terminology and provided relevant terminology within the scientific and engineering streams, focusing on health monitoring and management. The document further presented a perspective on technology development as it related to aircraft health monitoring and management. The latter is driven by the requirement for increased aircraft safety, reliability, enhanced performance and platform availability at reduced cost. Sensors and sensor concepts that have the potential of advancing autonomous sensor networks within a health monitoring and management capability have also been introduced and discussed. Such sensors included low (Nano, MEMS, RFID) and high technical readiness level (piezo and fiber optic sensors). Implementation of such presented concepts, technologies, and systems within the commercial or military sectors, continues to be limited due to several challenges including size, weight, power requirements, qualification and certification. 


\section{References}

[1] Alice Park, “The Science of Growing Body Parts," Health \& Science, TIME, 1 November 2007 ,

(http:/ / www.time.com/ time/ health/ article/ 0,8599,1679115,00.html), Retrieved on 26 April 2011.

[2] Joshua Topolsky, "Prosthetic-Limbed Runner Disqualified from Olympics," ENGADGET, 17 January 2008 ,

(http:/ / www.engadget.com/ 2008/ 01/ 17/ prosthetic-limbed-runner-disqualifiedfrom-olympics/ ), Retrieved on 26 April 2011.

[3] W. French Anderson, “Human Gene Therapy," Science, Vol. 256, No. 5058, pp. 808-813, May 1992.

[4] Richard P. Wool, “Self-Healing Materials: A Review," Soft Matter, Vol. 4, pp. 400-418, 2008.

[5] "Biological system", (en.wikipedia.org/ wiki/ Biological_system), Retrieved on 26 April 2011.

[6] Christopher K. Mathews, K.E.Van Holde and Kevin G. Ahern, Biochemistry, pg. 63, Addison Wesley Longman, Inc., 2000.

[7] Joel Moses, "Foundational Issues in Engineering Systems: A Framing Paper," MIT Engineering Systems Symposium, MIT, Cambridge, Mass. USA, March 29-31, 2004.

[8] Joanne fox, "what is bioinformatics," The science Creative Quarterly, Issue 6, 2011(http:/ / www.scq.ubc.ca/ what-is-bioinformatics/), Retrieved on 26 April 2011.

[9] Ryszard Lobinski, et al., "Metallomics: Guidelines for Terminology and Critical Evaluation of Analytical Chemistry Approaches (IUPAC Technical Report), Chemistry international: The New Magazine of the International Union of Pure and Applied Chemistry (IUPAC), Pure and Applied Chemistry, Vol. 82, No. 2, pp. 493$504,2010$.

[10] Simon R. Downes, “Learning the basic sciences," Basic Science Study Log, September 9, 2010, (http:/ / myroadtomedicalschool.blogspot.com/2010_09_01_archive.html), Retrieved on 26 April 2011.

[11] Paul Fitzgerald, "Borescope Inspection of Aircraft Turbines," The Science of Remote Visual Inspection, Remote Visual Inspection - The Leading Remote Visual Inspection Resource, 3 August 2009, (http:/ / www.remotevisualinspection.org/ 2009/ 08/ 03/ borescope-inspection/ ), Retrieved on 26 April 2011.

[12] Bitter and Sour, "Living a normal life as a cyborg," SBB Visual impact, May 2010. (http:/ / stupidbigblog.blogspot.com/ 2010/ 05/ living-normal-life-as-cyborg.html), Retrieved on 26 April 2011.

[13] "Definition of Diagnostics", (http:/ / www.thefreedictionary.com/ diagnostics), Retrieved on 29 April 2011.

[14] Definition of Diagnosis, Medicine Net.com, (http:/ / www.medterms.com/ script/ main/ ), Retrieved on 29 April 2011.

[15] "Definition of Prognostic," (http:/ / www.thefreedictionary.com/ Prognostics), Retrieved on 29 April 2011.

[16] Dave Korsmeyer, “Actuator Prognostics," NASA Ames Research Center 
(http:/ / ti.arc.nasa.gov/ tech/ dash/ pcoe/ actuator-prognostics/ research/ ), Retrieved on 29 April 2011.

[17] Industry Canada, "Aircraft Systems Diagnostics, Prognostics and Health Management Technology Insight Document," Industry Canada Contract 5011101, Vol. 2, 16 December 2004.

[18] Michael Pecht and Jie Gu, "Health Assessment and Prognostics of Electronic Products: An Alternative to Traditional Reliability Prediction Methods," Electronics Cooling (Dedicated to Thermal Management in the Electronics Industry), pp. 1-7, 9 May 2009.

[19] Farrar, Charles R. and Keith Worden, "An Introduction to Structural Health Monitoring," Philosophical Transactions of the Royal Society A (London: Royal Society Publishing) Vol. 365, pp. 303-315, 1851.

[20] "Structural Reliability and Nondestructive Characterization," McCormick - Theoretical and Applied Mechanics, Northwestern University,

(http:/ / www.tam.northwestern.edu/ wmaster/ research/ nde.html), Retrieved on 29 April 2011.

[21] Expeditionary Logistics, eLOG 21, "Conditioned-Based Maintenance Plus (CBM+)," Joint Vision 2020, Fact Sheet, (https:/ / acc.dau.mil/ ), Retrieved on 20 July 2010.

[22] Romano Patrick-Aldaco, "A Model Based Framework for Fault Diagnosis and Prognosis of Dynamical Systems with an Application to Helicopter Transmissions," Doctor of Philosophy Dissertation, Electrical and Computer Engineering, Georgia Institute of Technology, August 2007.

[23] S. Beeby, G. Ensell, M. Kraft and N. White, MEMS Mechanical Sensors, Microelectromechanical systems series, Artech House Inc. 2004, ISBN 1-58053-536-4.

[24] E. Udd, "An Overview of Fiber-Optic Sensors," Review of Scientific Instruments, Vol. 66 Issue 8, pp. 4015-5030, August 1995.

[25] J.F. Tressler, S. Alkoy, R.E. Newnham, "Piezoelectric sensors and sensor materials," Journal of Electroceramics, Vol, 2, Issue 4, pp. 257-272, 1998.

[26] V. Giurgiutiu, “Tuned lamb wave excitation and detection with piezoelectric wafer active sensors for structural health monitoring," Journal of Intelligent Material Systems and Structures, Vol. 16, No. 4, pp. 291-305, 2005.

[27] I. Sage, L Humberstone, I Oswald, P Lloyd and G Bourhill, "Getting light through black composites: embedded triboluminescent structural damage sensors," Smart Mater. Struct. Vol. 10, pp. 332-337, 2001.

[28] S. Beard, X. Q. Peter, M. Hamilton and D. C. Zhang, Acellent Technologies, Inc. (2005).

[29] Kazuhiro Otsuka, Xiaobing Ren, "Recent developments in the research of shape memory alloys," Intermetallics, Vol. 7, pp. 511-528, 1999.

[30] Chang, Neng-Kai Su, Chi-Chung Chang, Shuo-Hung, "Fabrication of single-walled carbon nanotube flexible strain sensors with high sensitivity," Applied Physics Letters, Vol. 92, Issue 6, pp. 063501 - 063501-3, 2008, ISSN: 0003-695.

[31] Sharp, P. K. Rowlands, D. E. and Clark, G., "Evaluation of Innovative NDI Methods for Detection of Service Simulation Cracking”, Defence Science and Technology Organization, Report DSTO-TR-0366., August 1996.

[32] Dharap, P., Li, Z., Nagarajaiah, S., and Barrera, E. "Nanotube film based on SWNT for macrostrain sensing," Nanotechnology Journal, Vol. 15 Issue 3, pp. 379-382, 2004. 
[33] Vemuru, S. M., Wahi, R., Nagarajaiah, S. and Ajayan, P.M. "Strain sensing using a multiwalled carbon nanotube film," The Journal of Strain Analysis for Engineering Design, Vol. 44, Issue 7, DOI 10.1243/ 03093247.SA535, 555-562, 2009.

[34] W. Zhang, J. Suhr and N. Koratkar, "Carbon nanotube/ polycarbonate composites as multifunctional strain sensors," Journal of Nanoscience and Nanotechnology, Vol. 6, Issue 4, pp. 960-964, 2006.

[35] Inpil Kang, Mark J Schulz, Jay H. Kim, Vesselin Shanov and Donglu Shi, "A carbon nanotube strain sensor for structural health monitoring," Smart Mater. Struct. Vol. 15, pp. 737-748, 2006.

[36] Alexopoulos N.D., Bartholome C., Poulin P., Marioli-Riga Z., Composites Science and Technology Vol. 70, pp. 260-71, 2010.

[37] Erik T Thostenson and Tsu-Wei Chou1, "Real-time in situ sensing of damage evolution in advanced fiber composites using carbon nanotube networks," Nanotechnology, Vol. 19, 215713, 2008.

[38] B. Ashrafi, Nezih Mrad and A. Johnston, "Evaluation of Nanotechnology for Structural Health Monitoring of Airframe Structures," National Research Council Publication, Number LTR-SMPL-2010-0086. April 2010.

[39] B. Ashrafi, L. Johnson, Y. Martinez-Rubi, M. Martinez, N. Mrad, “CNT-modified Epoxy Thin Films for Continuous Crack Monitoring of Metallic Structures,” In progress, 2011.

[40] “Definition of Smart”, Cambridge Advanced Learner's Dictionary, (http:/ / dictionary.cambridge.org/ results.asp?searchword=smart), Retrieved on 29 April 2011.

[41] National Institute of Standards and Technology," IEEE 1451 Smart Transducer Interface Standard,” IEEE 1451 Website ( http:/ / ieee1451.nist.gov/ ) , Retrieved on 29 April 2011.

[42] T Niblock, B. C. Laskow ski, H. Surangalikar, J. Moreno, “STape (Smart Tape)," proc 6th International Aircraft Corrosion Workshop, 24 - 27 August 2004, Solomons, Maryland, USA, 2004.

[43] Trevor Niblock, Harshal S. Surangalikar, Jeffrey Morse, Bernard C Laskowski, Jose Moreno, "AMSN (Arrayed Multiple Sensor Networks) for Material and Structural Prognostics”, Materials Science \& Technology 2004, New Orleans, Louisiana, September 2004

[44] Mourad El-Gamal, "MEMS in Aircraft Engine Monitoring - A Humidity Sensor," Defence R\&D Canada - Atlantic, Contract Report, DRDC Atlantic CR 2011-069, April 2011.

[45] Do-Yun Kim, Byung-Jun Jang, Hyun-Goo Yoon, Jun-Seok Park and Jong-Gwan Yook, "Effects of Reader Interference on the RFW Interrogation Range", Microwave Conference, pp. 728 - 731, 2007.

[46] K. G. Ong, C. A. Grimes, C. L. Robbins and R. S. Singh, "Design and application of a wireless, passive, resonant-circuit environmental monitoring sensor," Sensors and Actuators A: Physical, Vol. 93, Issue 1, pp. 33-43 25 August 2001.

[47] A. Marincak, T. Benak, M. Fischer, K. Kraemer, "Application of the Surface Mountable Crack Sensor (SMCS) System for the Canadian Forces CP140 Aurora Aircraft Aft Pressure Bulkhead (FS1117),” LM - CP140 FS1117 SMCS Rev 1, 14 February 2008. 
[48] Nezih Mrad, "State of Development of Advanced Sensory Systems for Structural Health Monitoring Applications," Proceedings of the NATO RTO AVT-144 Workshop on Enhanced Aircraft Platform Availability Through Advanced Maintenance Concepts and Technologies, Vilnius, Lithuania, 3-5 October 2006 (DRDC Atlantic SL-2008-260).

[49] S.J. Beard, A. Kumar, P.X. Qing, H.L. Chan, C. Zhang and T.K. Ooi, "Practical Issues in Real-World Implementation of Structural Health Monitoring Systems," Proceedings of SPIE on Smart Structures and Material Systems, March 2005.

[50] A. Kumar, S.J. Beard, P.X. Qing, H.L. Chan, T. Ooi, Stephen A. Marotta and F.K. Chang, "A Self-Diagnostic Structural Health Monitoring System for Composite Structures," SEM X International Conference, California, June 2004.

[51] Xinlin P. Qing, Shawn J. Beard, Roy Ikegami, Fu-Kuo Chang, Christian Boller, "Aerospace Applications of SMART Layer Technology" Encyclopedia of Structural Health Monitoring, Wiley Publications, 2009

[52] Mrad N. "Optical sensor technology: introduction and evaluation and application," In: Schwartz M, editor, Encyclopedia of smart materials, Vol. 2. New York: Jbhn Wiley \& Sons, Inc., p. 715-37, 2002.

[53] E. Udd, "Fiber Optic Sensors - An Introduction for Engineers and Scientists," John Wiley \& Sons, 2006.

[54] Lufan Zou, Xiaoyi Bao, Fabien Ravet, and Liang Chen, "Distributed Brillouin fiber sensor for detecting pipeline buckling in an energy pipe under internal pressure," Applied Optics, Vol. 45, Issue 14, pp. 3372-3377, 2006.

[55] I. Perez, "Fiber Sensors for Aircraft Monitoring," Naval Air Warfare Center Aircraft Division, DTIC Doc: AD-A375814, 1999. 


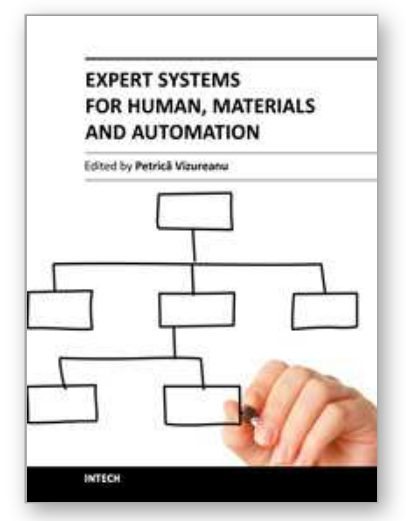

\author{
Expert Systems for Human, Materials and Automation \\ Edited by Prof. PetricÄ $f$ Vizureanu
}

ISBN 978-953-307-334-7

Hard cover, 392 pages

Publisher InTech

Published online 10, October, 2011

Published in print edition October, 2011

The ability to create intelligent machines has intrigued humans since ancient times, and today with the advent of the computer and 50 years of research into Al programming techniques, the dream of smart machines is becoming a reality. The concept of human-computer interfaces has been undergoing changes over the years. In carrying out the most important tasks is the lack of formalized application methods, mathematical models and advanced computer support. The evolution of biological systems to adapt to their environment has fascinated and challenged scientists to increase their level of understanding of the functional characteristics of such systems. This book has 19 chapters and explain that the expert systems are products of the artificial intelligence, branch of computer science that seeks to develop intelligent programs for human, materials and automation.

\title{
How to reference
}

In order to correctly reference this scholarly work, feel free to copy and paste the following:

Nezih Mrad and Rim Lejmi-Mrad (2011). Advances in Health Monitoring and Management, Expert Systems for Human, Materials and Automation, Prof. PetricÄ $f$ Vizureanu (Ed.), ISBN: 978-953-307-334-7, InTech, Available from: http://www.intechopen.com/books/expert-systems-for-human-materials-andautomation/advances-in-health-monitoring-and-management

\section{INTECH}

open science | open minds

\author{
InTech Europe \\ University Campus STeP Ri \\ Slavka Krautzeka 83/A \\ 51000 Rijeka, Croatia \\ Phone: +385 (51) 770447 \\ Fax: +385 (51) 686166 \\ www.intechopen.com
}

\author{
InTech China \\ Unit 405, Office Block, Hotel Equatorial Shanghai \\ No.65, Yan An Road (West), Shanghai, 200040, China \\ 中国上海市延安西路65号上海国际贵都大饭店办公楼 405 单元 \\ Phone: +86-21-62489820 \\ Fax: +86-21-62489821
}


(C) 2011 The Author(s). Licensee IntechOpen. This is an open access article distributed under the terms of the Creative Commons Attribution 3.0 License, which permits unrestricted use, distribution, and reproduction in any medium, provided the original work is properly cited. 